Article

\title{
The Influence of Main Design Parameters on the Overall Cost of a Gearbox
}

\author{
Ngoc-Pi Vu ${ }^{1, *(\mathbb{D})}$, Dinh-Ngoc Nguyen ${ }^{1}$, Anh-Tung Luu ${ }^{1}\left(\mathbb{D}\right.$, Ngoc-Giang Tran ${ }^{1}$, Thi-Hong Tran ${ }^{2}$, \\ Van-Cuong Nguyen ${ }^{3}$, Thanh-Danh Bui ${ }^{3}$ and Hong-Linh Nguyen ${ }^{4}$ \\ 1 Faculty of Mechanical Engineering, Thai Nguyen University of Technology, 3/2 street, Tichluong ward, \\ Thai Nguyen City 251750, Vietnam; dinhngoc@tnut.edu.vn (D.-N.N.); luuanhtung@tnut.edu.vn (A.-T.L.); \\ tranngocgiang@tnut.edu.vn (N.-G.T.) \\ 2 Faculty of Mechanical Engineering, Nguyen Tat Thanh University, 300A Nguyen Tat Thanh Street, Ward 13, \\ District 4, Ho Chi Minh City 754000, Vietnam; hongtt@ntt.edu.vn \\ 3 Faculty of Mechanical Engineering, University of Transport and Communications, \\ Hanoi City 11512, Vietnam; nguyencuong@utc.edu.vn (V.-C.N.); Danhdaiduong@utc.edu.vn (T.-D.B.) \\ 4 Faculty of Mechanical Engineering, Electric power University, 235 Hoang Quoc Viet Street, \\ Hanoi City 122300, Vietnam; linhnh@epu.edu.vn \\ * Correspondence: vungocpi@tnut.edu.vn; Tel.: +84-974905578
}

Received: 29 February 2020; Accepted: 24 March 2020; Published: 30 March 2020

check for updates

\begin{abstract}
This study is aimed at determining optimum partial gear ratios to minimize the cost of a three-stage helical gearbox. In this work, eleven input parameters were investigated to find their influence on the optimum gear ratios of the second and the third stages $\left(u_{2}\right.$ and $\left.u_{3}\right)$. To reach the goal, a simulation experiment was designed and implemented by a cost optimization program. The results revealed that in addition to the input parameters, their interactions also have important effects in which the total ratio gearbox ratio $\left(u_{t}\right)$ and the cost of shaft $\left(C_{s}\right)$ have the most impact on $u_{2}$ and $u_{3}$ responses, respectively. Moreover, the proposed models of the two responses are highly consistent to the experimental results. The proposed regression equations can be applied to solve optimization cost problems.
\end{abstract}

Keywords: gearbox; gear ratio; optimum gearbox design; three-stage helical gearbox

\section{Introduction}

In gearbox optimization design, determining optimum gear ratios has been a greatly important task. It can be explained by the fact that the size, the mass, and therefore, the cost of a gearbox is significantly affected by the gear ratios. To illustrate, Figure 1 shows the relation between the gear mass and the gear ratio of the second stage $u_{2}$ [1]. It can be seen from the figure that with the optimum value of $u_{2}\left(u_{2}=2\right)$, the mass of gears is merely about $178(\mathrm{~kg})$ whereas it reaches about $275(\mathrm{~kg})$ when $u_{2}=6$. Therefore, there has been various research work dealing with optimizing gear ratios so far [1-11]. The methodology of gear ratio optimization can basically be divided into three groups, e.g., graph method, practical method, and model method. The oldest method is the graph method [2,12], whereby the gear ratios are found based on the graph of the relationship between the component ratios and the total gearbox ratio. Figure 2 is an example of this method in which the gear ratios of the first and the second stages $u_{1}$ and $u_{2}$ of a three-stage helical gearbox are determined graphically. The practical method is introduced in [13], in which the optimum gears are determined based on the actual data from gearbox companies. For example, the mass of a two-stage helical gearbox is minimum when the ratio of the center distances of the second to the first stage is 1.4-1.6 [13]. From that comment, the optimum gear ratios are given. The most common method is the model method [3,4,14-16]. In this method, models for calculating optimum gear ratios are determined by solving optimum problems with different target 
functions such as minimal gearbox length [3,4,15], minimal mass of gears [4] or minimal gearbox cross section $[4,14,16]$.

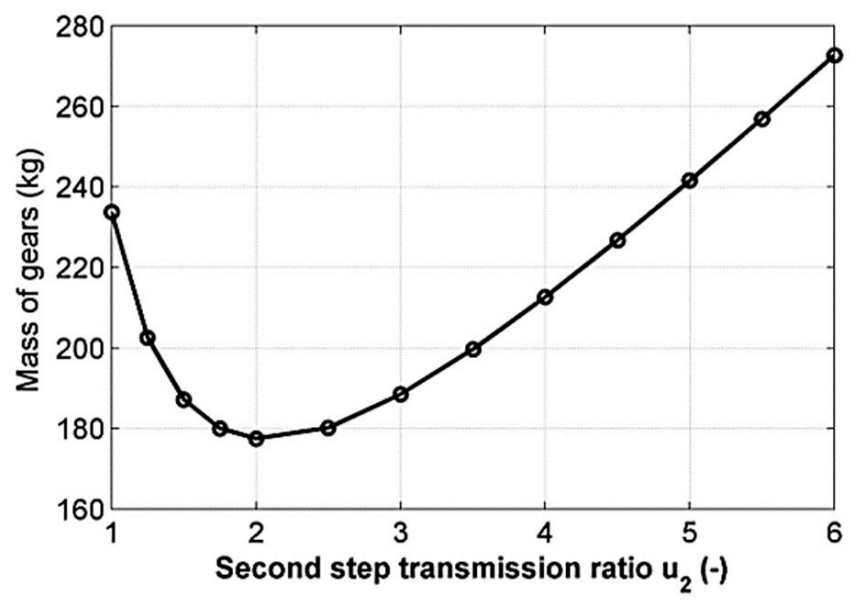

Figure 1. Gear mass versus second stage gear ratio [1].

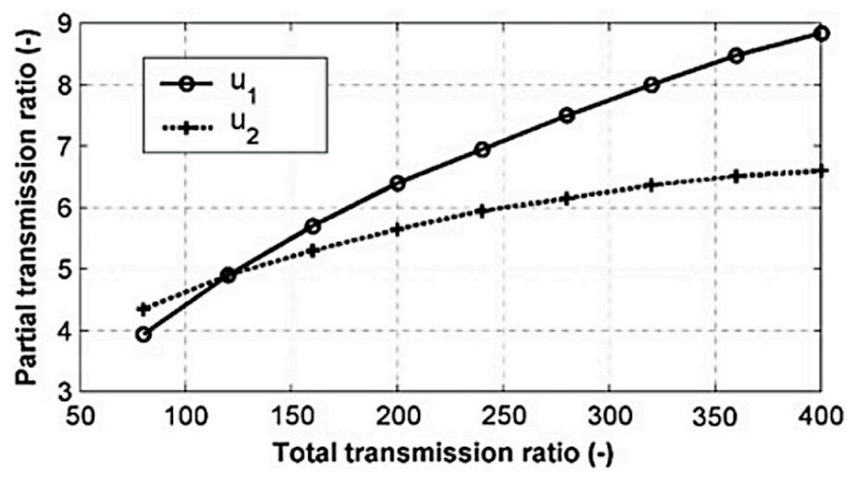

Figure 2. Partial gear ratios versus total gearbox ratio.

In literature these studies have investigated various levels of gear stages such as two-stage gearboxes [17,18], three-stage gearbox [4,14], and four-stage gearboxes [19]. Also, the determination of optimum gear ratios of bevel gearbox was carried in [20-23]. Recently, the optimum partial gear ratios have been found for mechanical driven systems using a gearbox and a chain drive $[5,9,23]$ or a V-belt drive $[22,24,25]$.

As previously mentioned, the optimal gear ratios directly impact the cost of the gearbox. However, up to now, there has been no research on calculating the optimal gear ratios with cost objective function. For this reason, this article presents a study on cost optimization in terms of finding the optimum gear ratio of three-stage Helical Gearboxes. The objective functions selected were the optimum gear ratios for second and third stage gears. Eleven input parameters were taken to investigate each parameter's influence and their interaction on the objective functions. A simulation experiment was planned using computer program to carry out the above issue.

\section{Optimization Problem}

\subsection{Cost Analysis of Three-Stage Helical Gearbox}

In practice, the cost of a gearbox depends on many cost elements, including the cost of the casing, shafts and gears, and bearings. However, due to the complicated cost calculation, the cost of bearings has not been considered in this study. As a result, the cost of a three-stage helical gearbox, namely $C_{g b}$, can be calculated as the Equation (1): 


$$
C_{g b}=C_{g}+C_{g h}+C_{s}
$$

where $C_{g}, C_{g h}$, and $C_{s}$ indicate the cost of gears, the cost of gearbox housing and the cost of shafts respectively.

Theoretically, the cost of a gear (the price of a gear) includes material costs, machining costs, heat treatment costs, labor costs including management and overhead costs, etc. The gear cost also depends on the gear shape and the gear size. The above component costs help to calculate the cost of a gear. In addition, in practice, the gear cost is usually calculated by unit price per kilogram and it varies by company policy and periodically. Therefore, in this study, the gear cost is investigated as a variable and calculated by the Equation (2):

$$
C_{g}=c_{g \cdot m} \cdot m_{g}
$$

in which, $c_{g . m}$ is the cost per a kilogram of gears (USD $\left./ \mathrm{kg}\right)$, and $m_{g}$ is representative for the mass of all gears in the gearbox $(\mathrm{kg})$.

The cost of gearbox housing can be determined by Equation (3):

$$
C_{g h}=c_{g h \cdot m} \cdot m_{g h}
$$

in this situation, $c_{g h . m}$ is the cost per a kilogram of gearbox housing (USD $/ \mathrm{kg}$ ), and $m_{g h}$ is the mass of the gearbox housing $(\mathrm{kg})$.

Finally, the cost of shafts is determined by Equation (4):

$$
C_{s}=c_{s . m} \cdot m_{s}
$$

where $c_{s . m}$ is the cost per a kilogram of shaft (USD $/ \mathrm{kg}$ ), and $m_{s}$ is the mass of all shafts in the gearbox $(\mathrm{kg})$.

Based on previously mentioned equations, it can be drawn that in order to get the cost of the gearbox $\left(C_{g b}\right)$ two factors should be identified. The first is the cost per a kilogram of gears, gearbox housing, and shafts which are varied according to the market. The second is the mass of gears, the gearbox housing, and shafts corresponding to $m_{g}, m_{g h}$, and $m_{s}$. However, it is noticed that the first factor is beyond the scope of this study, because it depends on the price of commercial markets. Then the later will be obtained by the detailed calculations in the next part of this study.

\subsection{The Determination of Gearbox Housing Mass}

The mass of gearbox housing $\left(m_{g h}\right)$ can be simply calculated by using Equation (5):

$$
m_{g h}=\rho_{g h} \cdot V_{g h}
$$

where, $\rho_{g h}$ is the weight density of gearbox housing materials referred in Table $1 ; V_{g h}$ is the volume of the gearbox housing $\left(\mathrm{m}^{3}\right)$.

Table 1. Weight density of used materials.

\begin{tabular}{ccc}
\hline$\rho_{g h}\left(\mathrm{~kg} / \mathrm{m}^{3}\right)$ & $\rho_{g}\left(\mathrm{~kg} / \mathrm{m}^{3}\right)$ & $\rho_{s}\left(\mathrm{~kg} / \mathrm{m}^{3}\right)$ \\
\hline 7.2 & 7.82 & 7.85 \\
\hline
\end{tabular}

Figure 3 presents the schematic relations of the gearbox housing dimensions. It is realized that the shape of gearbox housing is constructed by various component rectangulars. Hence, the volume of the gearbox housing can be determined by Equation (6).

$$
V_{g h}=2 \cdot V_{b}+2 \cdot V_{A 1}+2 \cdot V_{A 2}
$$


where $V_{b}, V_{A 1}$, and $V_{A 2}$ are the volumes of bottom housing, side A1, and side A2 (kg), respectively.

$$
\begin{gathered}
V_{b}=L \cdot B_{1} \cdot 1.5 \cdot S_{G} \\
V_{A 1}=L \cdot H \cdot S_{G} \\
V_{b}=B_{2} \cdot H \cdot S_{G}=\left(B_{1}-2 \cdot S_{G}\right) \cdot H \cdot S_{G}
\end{gathered}
$$

Substituting (7), (8), and (9) into (6) gets:

$$
V_{g h}=3 \cdot L \cdot B_{1} \cdot S_{G}+2 \cdot L \cdot H \cdot S_{G}+2 \cdot\left(B_{1}-2 \cdot S_{G}\right) \cdot H \cdot S_{G}
$$

In which, $L, H, B_{1}$, and $S_{G}$ can be determined by [26]:

$$
\begin{gathered}
L=\left(d_{w 11}+d_{w 21} / 2+d_{w 12} / 2+d_{w 22} / 2+d_{w 13} / 2+d_{w 22} / 2+22.5\right) / 0.975 \\
H=d_{w 23}+6.5 \cdot S_{G} \\
B_{1}=b_{w 2}+b_{w 3}+6 \cdot S_{G} \\
S_{G}=0.005 \cdot L+4.5
\end{gathered}
$$

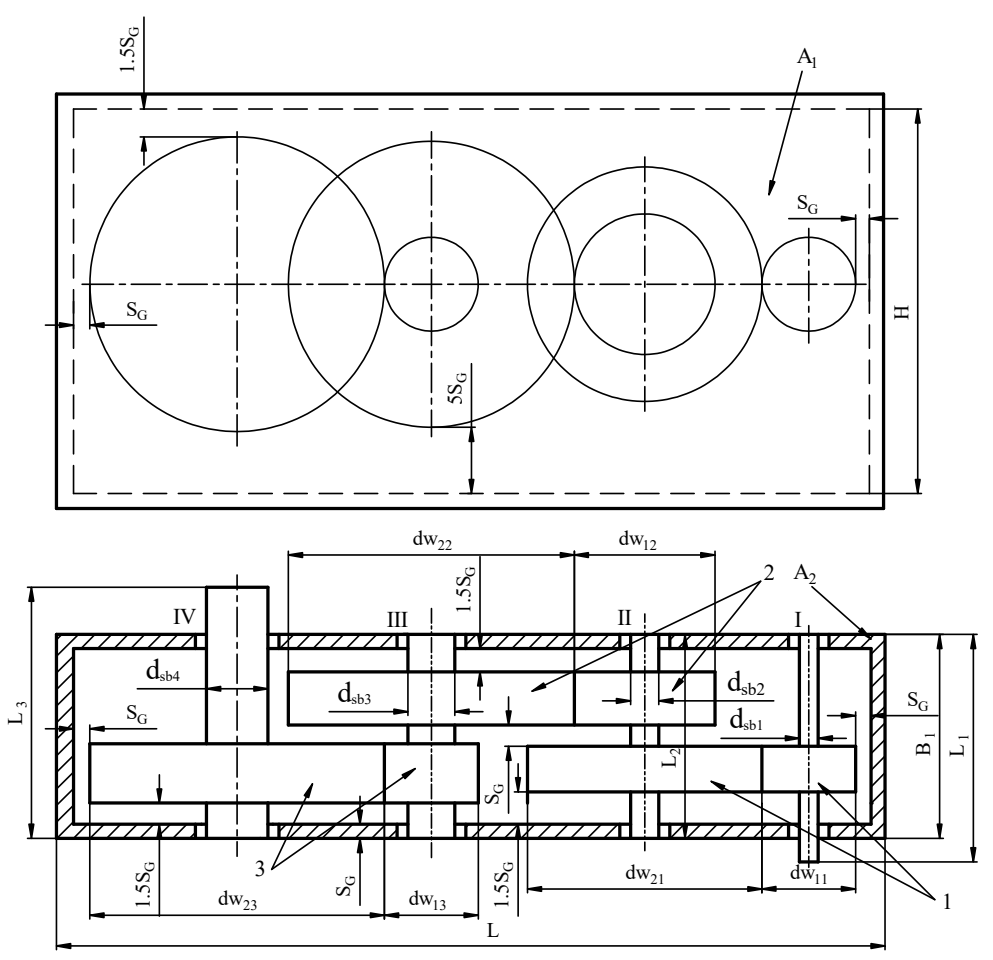

Figure 3. Schema for determination of gearbox mass.

\subsection{Gear Mass Calculations}

The studied gearbox includes three stages, consequently the total mass of gears can be summed up as follow:

$$
m_{g}=m_{g 1}+m_{g 2}+m_{g 3}
$$

where, $m_{g 1}, m_{g 2}$, and $m_{g 3}$ represent the gear mass of the first, the second, and the third stages $(\mathrm{kg})$ in which the first one can be determined by the following equations: 


$$
m_{g 1}=\rho_{g} \cdot\left(\frac{\pi \cdot e_{1} \cdot d_{w 11}^{2} \cdot b_{w 1}}{4}+\frac{\pi \cdot e_{2} \cdot d_{w 21}^{2} \cdot b_{w 1}}{4}\right)
$$

where $\rho_{g}$ is the weight density of gear material $\left(\mathrm{kg} / \mathrm{m}^{3}\right)$, cf. Table $1 ; e_{1}$ and $e_{2}$ are the volume coefficients of the drive gear and the driven gear of the first stage, respectively. In practice, $e_{1}$ and $e_{2}$ can be orderly selected by the values of 1 and $0.6 ; b_{w 1}$ is the width of the gears calculated by: $b_{w 1}=X_{b a 1} \cdot a_{w 1}(\mathrm{~mm})$.

Similarly, we have:

$$
m_{g 2}=\rho_{g} \cdot\left(\frac{\pi \cdot e_{1} \cdot d_{w 12}^{2} \cdot b_{w 2}}{4}+\frac{\pi \cdot e_{2} \cdot d_{w 22}^{2} \cdot b_{w 2}}{4}\right)
$$

and

$$
m_{g 3}=\rho_{g} \cdot\left(\frac{\pi \cdot e_{1} \cdot d_{w 13}^{2} \cdot b_{w 3}}{4}+\frac{\pi \cdot e_{2} \cdot d_{w 23}^{2} \cdot b_{w 3}}{4}\right)
$$

where $b_{w 22}$ and $b_{w 33}$ are the gear widths which can be determined in order by $(\mathrm{mm}) ; b_{w 22}=X_{b a 2} \cdot a_{w 2}$ and $b_{w 3}=X_{b a 3} \cdot a_{w 3}$.

\subsection{Shaft Mass Calculation}

It is known that a three stage gearbox contains four shafts constructing three stages. For this reason, the mass of the gearbox shafts can be determined by:

$$
m_{s}=m_{s 1}+m_{s 2}+m_{s 3}+m_{s 4}
$$

In which,

$$
\begin{aligned}
& m_{s 1}=\rho_{s} \cdot \pi \cdot d_{s 1}^{2} \cdot l_{s 1} / 4 \\
& m_{s 2}=\rho_{s} \cdot \pi \cdot d_{s 2}^{2} \cdot l_{s 2} / 4 \\
& m_{s 3}=\rho_{s} \cdot \pi \cdot d_{s 3}^{2} \cdot l_{s 3} / 4 \\
& m_{s 4}=\rho_{s} \cdot \pi \cdot d_{s 4}^{2} \cdot l_{s 4} / 4
\end{aligned}
$$

$m_{s 1}, m_{s 2}, m_{s 3}$, and $m_{s 4}$ are the mass of shafts $1,2,3$, and 4 of the gearbox $(\mathrm{kg})$ respectively; $\rho_{s}$ is the weight density of shaft material (cf. Table 1$) ; l_{s 1}, l_{s 2}, l_{s 3}$, and $l_{s 4}$ are orderly the length of shaft $1,2,3$, and 4 of the gearbox established by (cf. Figure 1):

$$
\begin{gathered}
l_{s 1}=B_{1}+1.2 \cdot d_{s 1} \\
l_{s 1}=l_{s 2}=B_{1} \\
l_{s 4}=B_{1}+1.2 \cdot d_{s 4}
\end{gathered}
$$

In the above equations [12]:

$$
\begin{aligned}
& d_{s 1}=\left[T_{11} /(0.2 \cdot[\tau])\right]^{1 / 3} \\
& d_{s 2}=\left[T_{12} /(0.2 \cdot[\tau])\right]^{1 / 3} \\
& d_{s 3}=\left[T_{13} /(0.2 \cdot[\tau])\right]^{1 / 3} \\
& d_{s 4}=\left[T_{14} /(0.2 \cdot[\tau])\right]^{1 / 3}
\end{aligned}
$$

where $[\tau]$ is the allowable shear stress. In this study, its value is chosen as $[\tau]=17 \mathrm{MPa}$. 


\subsection{Determination of the Centre Distances of the Gear Stages}

In addition to the module of gears, center distance is also an important factor for designing as well as optimizing gearbox. According to [12], the center distance of the i stage of the gearbox can be calculated by equation (31):

$$
a_{w i}=k_{a} \cdot\left(u_{i}+1\right) \cdot \sqrt[3]{T_{1 i} \cdot k_{H \beta} /\left(\left[\sigma_{H i}\right]^{2} \cdot u_{i} \cdot X_{b a 1}\right)}
$$

where:

- $\quad k_{H \beta}$ is the contacting load ratio for pitting resistance selected by 1.1 [12];

- $\quad\left[\sigma_{H i}\right]$ is the allowable contact stress of the i stage (MPa);

- $\quad k_{a}$ is the material coefficient; As the gear material is steel, $k_{a}=43$;

- $\quad X_{b a 1}$ is the coefficient of wheel face width of the i stage;

- $\quad T_{1 i}$ is the torque on the drive shaft of the i stage $(\mathrm{Nmm})$ determined by:

$$
T_{1 i}=\frac{T_{r}}{\prod_{j=i}^{3}\left(u_{i} \cdot \eta_{h g}^{4-i} \cdot \eta_{b e}^{5-i}\right)}
$$

According to [12], the pinion and the gear pitch diameters of the i stage can be calculated by the value of the center distance as the following equations:

$$
\begin{gathered}
d_{w 1 i}=2 \cdot a_{w i} /\left(u_{1}+1\right) \\
d_{w 2 i}=2 \cdot a_{w i} \cdot u_{i} /\left(u_{i}+1\right)
\end{gathered}
$$

\subsection{Optimization Problem}

Based on previously mentioned analyses, it can be emphasized that in order to reduce the cost of gearbox, minimizing the objective function $\left(C_{g b}\right)$ or $C_{g b}$ should satisfy the following constraints:

$$
1 \leq u_{1} \leq 91 \leq u_{2} \leq 91 \leq u_{3} \leq 9
$$

It can be clarified that to solve the optimizing solution, it is essential to optimize the values of partial gear ratios of $u_{1}, u_{2}$, and $u_{3}$. On the other hand, we have the relation between transmission ratios and partial ratios, $u_{t}=u_{1} \cdot u_{2} \cdot u_{3}$. Hence, in this study, instead of optimizing all three mentioned partial ratios, the optimization of only two partial ratios $\left(u_{2}\right.$ and $\left.u_{3}\right)$ are considered. The partial ratio can be determined by equation: $u_{1}=u_{t} /\left(u_{2} \cdot u_{3}\right)$.

\section{Experimental Work}

To investigate the influences of factors on objective functions of $u_{2}$ and $u_{3}$, simulation experiments, namely screening experiments, are carried out. Eleven factors (or input parameters) listed in Table 2 are selected for the exploration. Low and high values are considered to test each input factor. As the experiment in this work is a simulation experiment, it is not necessary to reduce the number of experiments required to be performed like real experiments. Therefore, it is desired to perform full factorial design of $2^{11}$ instead of the Taguchi method as the usual practice. Nevertheless, the expecting function is not available in Minitab@19, therefore the model of $2^{11-4}$ and 1/16 fraction is purposely adopted. Consequently, $2^{11-4}=128$ tests for the simulation experiment are utilized. This method is also the way for the largest number of experiments. Moreover, the use of a screening design is aimed at eliminating influential parameters. This is the simplest method to determine the effects of parameters as well as their interactions on the target function. On the other hand, it is possible to provide mathematical models that the Taguchi method cannot. 
Table 2. Input parameters.

\begin{tabular}{lccccc}
\hline \multicolumn{1}{c}{ Real Factor } & Minitab ${ }^{\circledR} \mathbf{1 9}$ & Name & Unit & Low & High \\
\hline Total gearbox ratio & $\mathrm{A}$ & $u_{t}$ & - & 10 & 100 \\
Coefficient of wheel face width of stage 1 & $\mathrm{B}$ & $X_{b a 1}$ & - & 0.3 & 0.35 \\
Coefficient of wheel face width of stage 2 & $\mathrm{C}$ & $X_{b a 2}$ & - & 0.33 & 0.38 \\
Coefficient of wheel face width of stage 3 & $\mathrm{D}$ & $X_{b a 3}$ & - & 0.35 & 0.4 \\
Allowable contact stress of stage 1 & $\mathrm{E}$ & $A S_{1}$ & $\mathrm{MPa}$ & 350 & 420 \\
Allowable contact stress of stage 2 & $\mathrm{F}$ & $A S_{2}$ & $\mathrm{MPa}$ & 350 & 420 \\
Allowable contact stress of stage 3 & $\mathrm{G}$ & $A S_{3}$ & $\mathrm{MPa}$ & 350 & 420 \\
Output torque & $\mathrm{H}$ & $T_{o u t}$ & $\mathrm{Nm}$ & 1000 & 10000 \\
Cost of gearbox housing & $\mathrm{I}$ & $C_{g h}$ & $\mathrm{USD} / \mathrm{kg}$ & 1 & 5 \\
Cost of gears & $\mathrm{J}$ & $C_{g}$ & $\mathrm{USD} / \mathrm{kg}$ & 2 & 9 \\
Cost of shafts & $\mathrm{K}$ & $C_{s}$ & $\mathrm{USD} / \mathrm{kg}$ & 1.5 & 5 \\
\hline
\end{tabular}

The demonstration of the input parameters and the responses can be seen in Table 2, where the factors are orderly assigned as factors A, B, etc. The output responses are presented in Table 3.

Table 3. Experimental plans and output responses.

\begin{tabular}{|c|c|c|c|c|c|c|c|c|c|c|c|c|c|c|c|}
\hline Run Order & Center Pt & Blocks & $u_{t}$ & $X_{b a 1}$ & $X_{b a 2}$ & $X_{b a 3}$ & $A S_{1}$ & $A S_{2}$ & $A S_{3}$ & $T_{\text {out }}$ & $C_{g h}$ & $C_{g}$ & $C_{s}$ & $u_{2}$ & $u_{3}$ \\
\hline 1 & 1 & 1 & 30 & 0.35 & 0.38 & 0.4 & 350 & 420 & 350 & 1000 & 1 & 2 & 1.5 & 4.02 & 3.64 \\
\hline 2 & 1 & 1 & 100 & 0.35 & 0.33 & 0.36 & 420 & 350 & 420 & 1000 & 5 & 2 & 1.5 & 4.08 & 4.24 \\
\hline 3 & 1 & 1 & 100 & 0.3 & 0.33 & 0.4 & 420 & 350 & 350 & 1000 & 5 & 9 & 5 & 4.11 & 3.73 \\
\hline 4 & 1 & 1 & 30 & 0.35 & 0.33 & 0.4 & 350 & 350 & 350 & 1000 & 5 & 2 & 1.5 & 3.63 & 3.58 \\
\hline 5 & 1 & 1 & 100 & 0.3 & 0.33 & 0.36 & 350 & 420 & 350 & 1000 & 5 & 9 & 1.5 & 5.22 & 2.59 \\
\hline 6 & 1 & 1 & 30 & 0.35 & 0.38 & 0.4 & 420 & 350 & 350 & 10000 & 5 & 9 & 1.5 & 3.03 & 3.28 \\
\hline \multicolumn{16}{|c|}{ (Appendix A) } \\
\hline 127 & 1 & 1 & 30 & 0.3 & 0.38 & 0.4 & 420 & 420 & 420 & 10000 & 1 & 2 & 5 & 4.11 & 5.83 \\
\hline 128 & 1 & 1 & 100 & 0.3 & 0.38 & 0.36 & 420 & 350 & 350 & 10000 & 5 & 9 & 5 & 4.02 & 3.55 \\
\hline
\end{tabular}

\section{Results and Discussions}

\subsection{The Influence of Input Parameters and Their Interactions}

The evolution of the optimum gear ratio of the second step $\left(u_{2}\right)$ as functions of each input parameter is presented in Figure 4 . It is observed that $u_{2}$ increases when Total gearbox ratio $\left(u_{t}\right)$, Allowable contact stress of stage $2\left(A S_{2}\right)$, and Cost of shafts $\left(C_{s}\right)$ increase also. Nevertheless, for this tendency it is realized that Total gearbox ratio $\left(u_{t}\right)$ has greater influence than that of other factors. Conversely, $u_{2}$ decreases with the growth of Allowable contact stress of stage 1 and $3\left(A S_{1}\right.$ and $\left.A S_{3}\right)$, and Output torque $\left(T_{\text {out }}\right)$. Moreover, it is shown that Coefficients of wheel face width of stage 1,2 , and $3\left(X_{b a 1}, X_{b a 2}\right.$ and $\left.X_{b a 3}\right)$ do not have influence on $u_{2}$. Regarding to the case of $u_{3}$ (c.f. Figure $4 \mathrm{~b}$ ), the experimental results reveal that Cost of gears $\left(C_{g}\right)$ and Cost of shafts $\left(C_{S}\right)$ have a significant effect on the value of $u_{3}$. It means that $u_{3}$ develops when Cost of shafts rises or Cost of gears declines. Furthermore, the first five input parameters mentioned in Table 2 do not have impact on the evolution of $u_{3}$. It is noticed that the influence investigation of the input factors on response as previously mentioned do not take their interactions into account. This will be considered in the next part of the current study. 


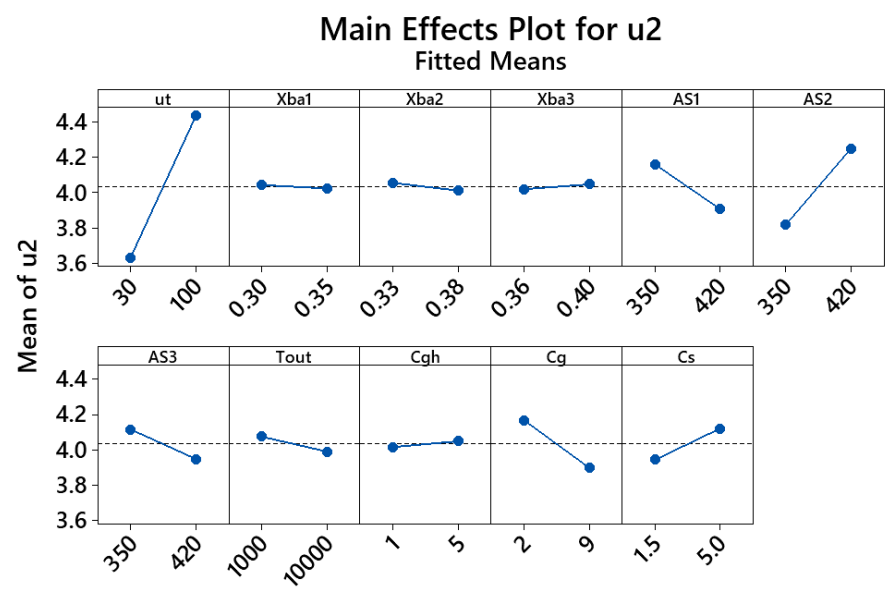

(a)

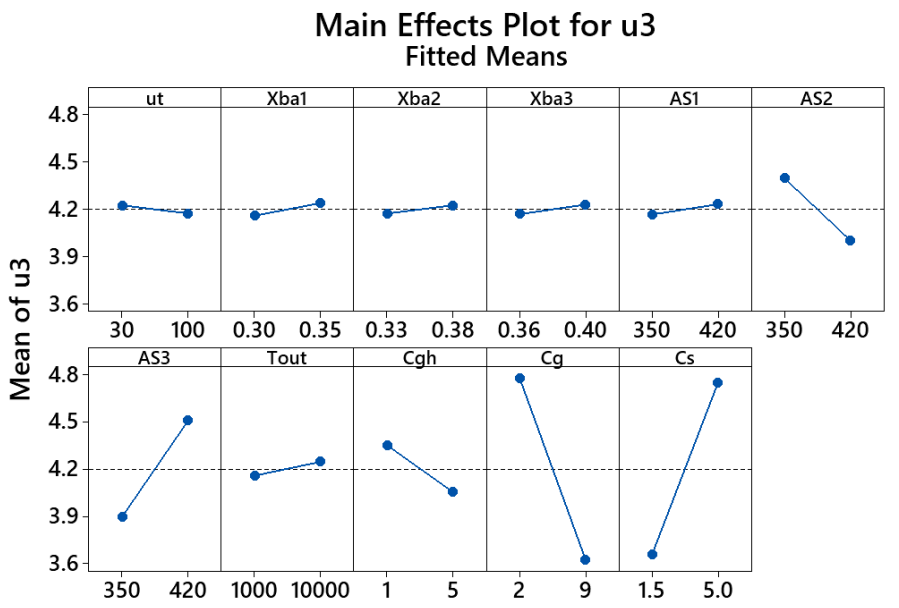

(b)

Figure 4. Main effects plot for (a) $u_{2}$ and (b) $u_{3}$.

Figure 5 a displays the interactions between the input parameters on the response of $u_{2}$. It is observed that the interactions between $u_{t}$ and some input parameters such as $\operatorname{AE}\left(u_{t}^{*} A S_{1}\right), \operatorname{AF}\left(u_{t}^{*} A S_{2}\right)$, $\mathrm{AG}\left(u_{t}^{*} A S_{3}\right), \mathrm{AK}\left(u_{t}^{*} C_{g}\right)$, and $\mathrm{AL}\left(u_{t}^{*} C_{s}\right)$ in both values of 30 and 100 has the most significant influence on the $u_{2}$ response, while the stable tendency is observed for the interactions between $u_{t}$ and remaining input parameters, e.g., $\mathrm{AB}\left(u_{t}{ }^{*} X_{b a 1}\right), \mathrm{AC}\left(u_{t}{ }^{*} X_{b a 2}\right), \mathrm{AD}\left(u_{t}{ }^{*} X_{b a 3}\right), \mathrm{AH}\left(u_{t}{ }^{*} T_{o u t}\right)$, and $\mathrm{AJ}\left(u_{t}{ }^{*} C_{g h}\right)$. Similarly, we can realize the interactions which have significant influence on the $u_{2}$ response but are lesser than the ones of $u_{t}$ like BF $\left(X_{b a 1}{ }^{*} A_{S 2}\right), \mathrm{BE}\left(X_{b a 1}{ }^{*} A_{S 1}\right), \mathrm{CL}\left(X_{b a 2}{ }^{*} C_{S}\right), \mathrm{CK}\left(X_{b a 2}{ }^{*} C_{g}\right), \mathrm{CF}\left(X_{b a 2}{ }^{*} A S_{2}\right), \mathrm{FH}\left(A S_{2}{ }^{*} T_{o u t}\right)$, FG $\left(A S_{2}{ }^{*} A S_{3}\right), \mathrm{FL}\left(A S_{2}{ }^{*} C_{s}\right), \mathrm{FK}\left(A S_{2}{ }^{*} C_{g}\right), \mathrm{FL}\left(A S_{2}{ }^{*} C_{S}\right), \mathrm{FJ}\left(A S_{2}{ }^{*} C_{g h}\right), \mathrm{HK}\left(T_{\text {out }}{ }^{*} C_{g}\right), \mathrm{GL}\left(A S_{3}{ }^{*} C_{s}\right), \mathrm{GJ}$ $\left(A S_{3}{ }^{*} C_{g h}\right)$, and $\mathrm{GH}\left(A S_{3}{ }^{*} T_{o u t}\right)$. Referring to the case of the response $u_{3}$ (cf. Figure $\left.5 \mathrm{~b}\right)$, it is visualized that the interactions $\mathrm{JK}\left(C_{g h}{ }^{*} C_{g}\right), \mathrm{JL}\left(C_{g h}{ }^{*} C_{s}\right), \mathrm{GK}\left(A S_{3}{ }^{*} C_{g}\right), \mathrm{GL}\left(A S_{3}{ }^{*} C_{s}\right), \operatorname{FK}\left(A S_{2}{ }^{*} C_{g}\right), \operatorname{FL}\left(A S_{2}{ }^{*} C_{s}\right), \mathrm{KL}$ $\left(C_{g}{ }^{*} C_{s}\right), \mathrm{BH}\left(X_{b a 1}{ }^{*} T_{o u t}\right), \mathrm{BL}\left(X_{b a 1}{ }^{*} C_{s}\right), \mathrm{DG}\left(X_{b a 3}{ }^{*} A S_{3}\right), \mathrm{EG}\left(A S_{1}{ }^{*} A S_{3}\right)$, and $\mathrm{EK}\left(A S_{1}{ }^{*} C_{g}\right)$ have significant influences on the $u_{3}$ response.

Figure 6 presents the Normal Plot of the standardized effects in which the relationship between the responses $\left(u_{2}\right.$ and $\left.u_{3}\right)$ and the input parameters as well as their interactions are exposed. Based on the results presented in the figure, it is seen that $u_{t}$ and $A S_{2}$ have the greatest influence on the response $u_{2}$ as previously documented. Furthermore, it is realized that, in addition to single input parameters as early presented $\left(u_{t}, A S_{2}, C_{s}, C_{g}, A S_{1}\right.$, and $\left.A S_{3}\right)$ the interactions of some input parameters also have both positive and negative impacts on the response of $u_{2}$. For instance, the increase in the interactions of $\mathrm{AK}, \mathrm{EL}, \mathrm{AJ}, \mathrm{AF}, \mathrm{BH}, \mathrm{HK}$, and GK leads to the augment of the $u_{2}$ response. Conversely, 
the decrease in the interactions of $\mathrm{AL}, \mathrm{KL}, \mathrm{EK}, \mathrm{AE}, \mathrm{JL}$, and $\mathrm{AG}$ causes the reduction of $u_{2}$ response. Considering the case of $u_{3}$, the results anew reveal that Cost of gears $\left(C_{g}\right)$ and Cost of shafts $\left(C_{S}\right)$ have dominant impact on the value of $u_{3}$ as mentioned above. Besides, the interactions between the input parameters also have influence in both positive and negative trends. For example, the response of $u_{3}$ is positively influenced by the interactions of $\mathrm{JK}, \mathrm{EK}$, and $\mathrm{BL}$, while being negatively affected by those of KL, GK, EG, and BH. Based on the results shown in the Normal Plot of the Standardized Effects, the parameters or interactions with insignificant influence can be eliminated, while those with strong impact are remained. The testing process can go further and in more detailse with the remained parameters. In these situations, the remained parameters are listed in Tables 4 and 5 in the case of $u_{2}$ and $u_{3}$, respectively.

\section{Interaction Plot for $\mathrm{u} 2$} Fitted Means

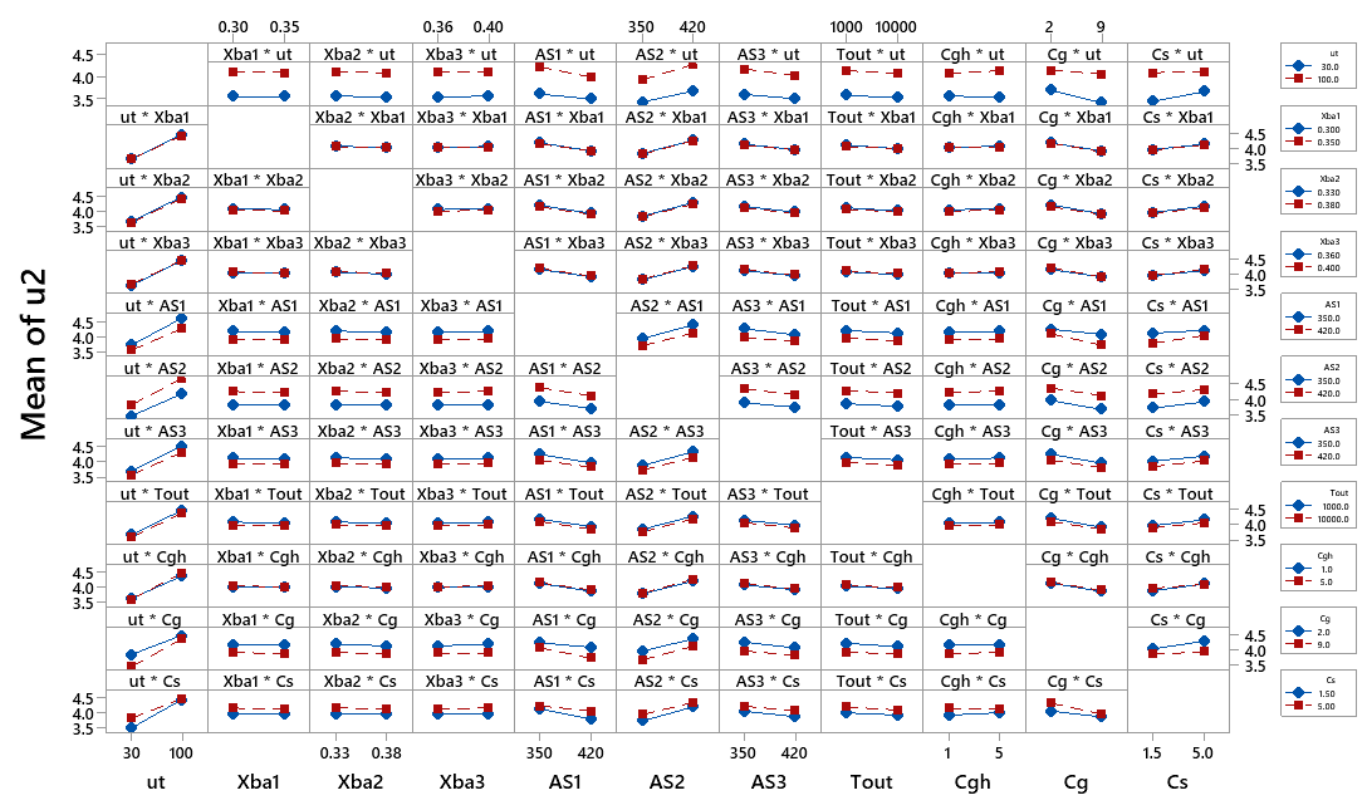

(a)

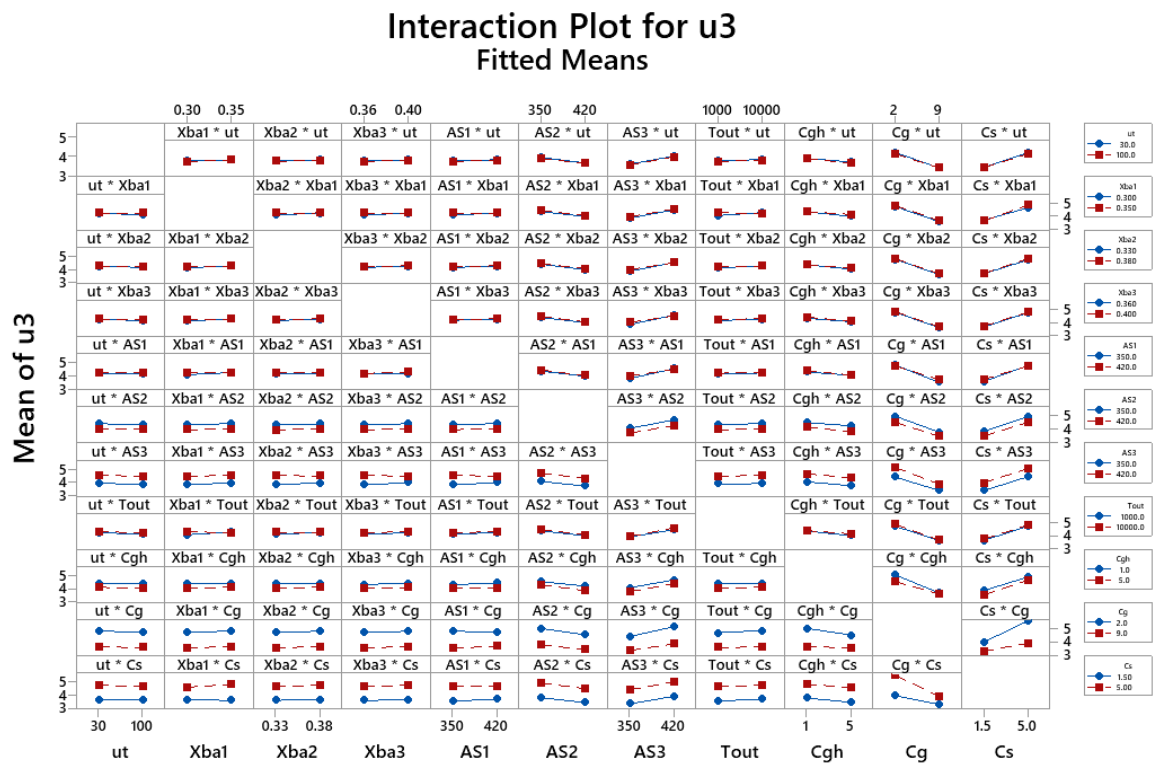

(b)

Figure 5. The interactions between input parameters on the response of $u_{2}$ (a) and $u_{3}(\mathbf{b})$. 


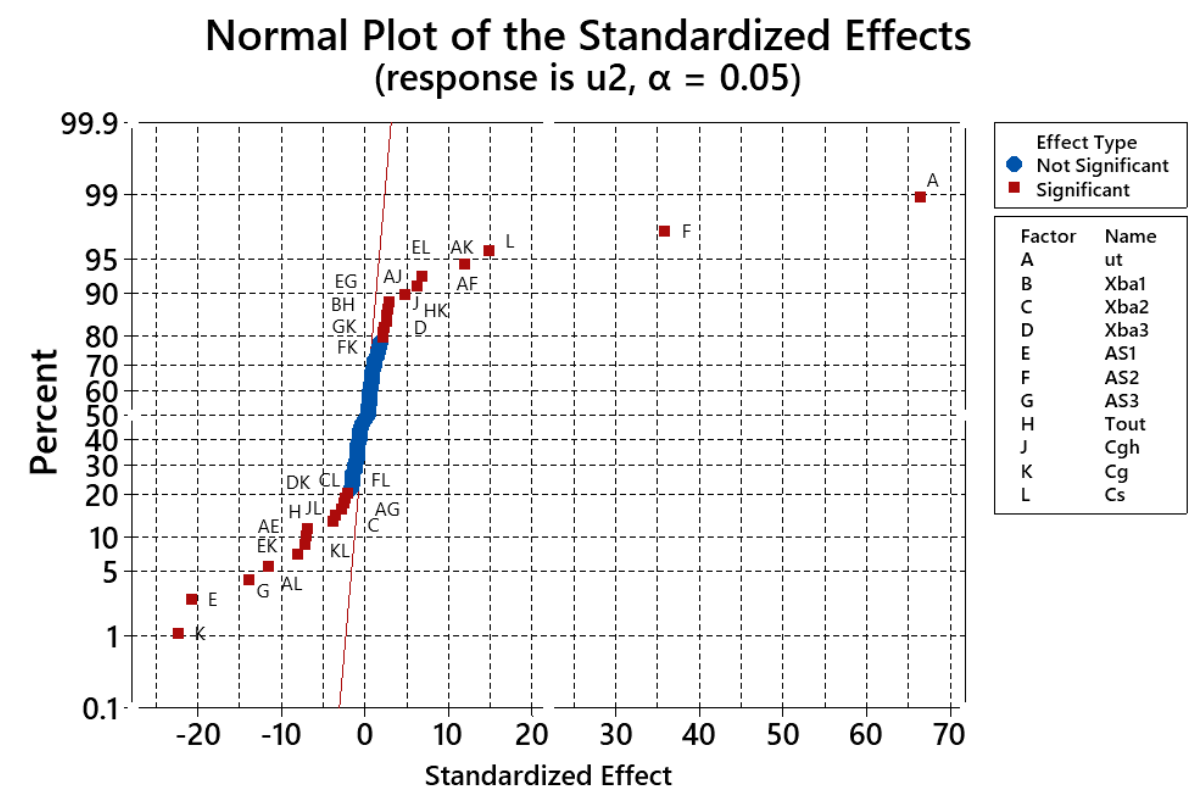

(a)

Normal Plot of the Standardized Effects (response is $u 3, \alpha=0.05$ )

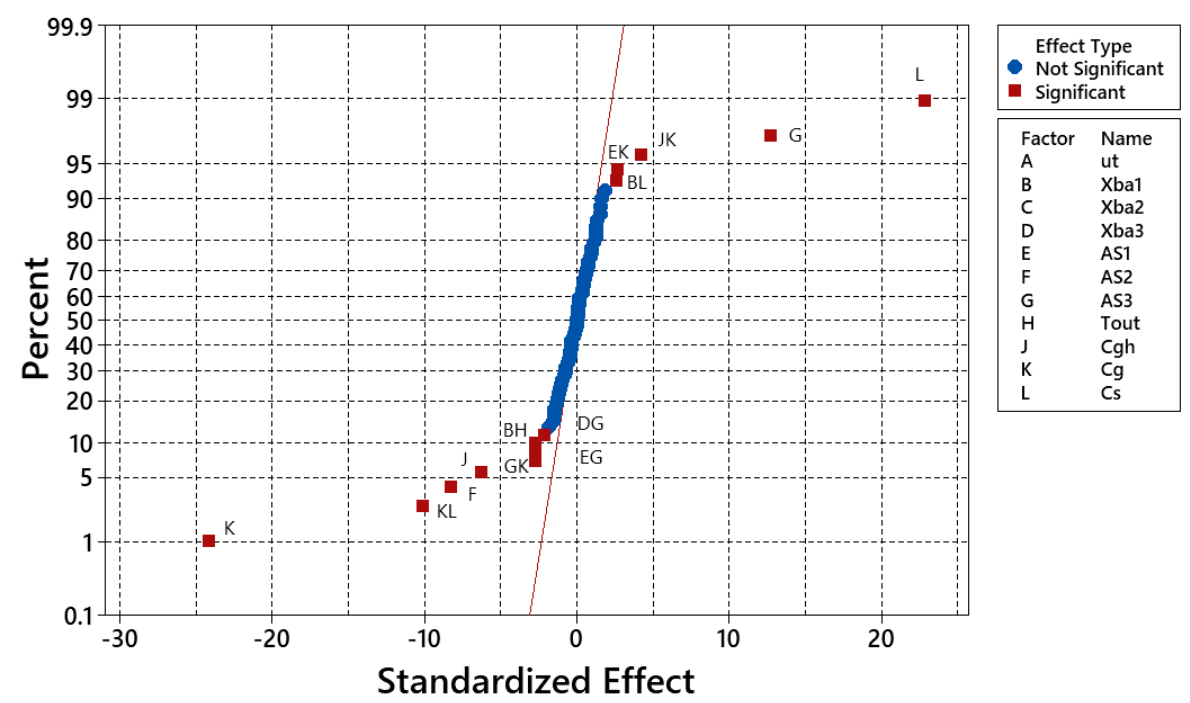

(b)

Figure 6. The evolution of response as a function of input parameters and their interactions (a) $u_{2}$ and (b) $u_{3}$

\subsection{Proposed Regression Model of the Response}

In order to achieve equations of the response $u_{2}$ and $u_{3}$, a regression process with two interaction factors is carried out using Minitab@19. The significance of this regression is $\alpha=0.05$. The estimated effects and the coefficients for $u_{2}$ response are exhibited in Table 4 where the factors with no influence on them are eliminated. It is noticed that if the effect of each input parameter or interaction has $p$-value higher than the significance of $\alpha$, it does not strongly impact the response. For example, the factor of $X_{b a 1}$ has $p$-value of 0.111 superior to $\alpha=0.05$, which means that $X_{b a 1}$ is not significant to the response $u_{2}$. The regression equation of the $u_{2}$ response is described by following model (Regression Equation in Uncoded Units): 


$$
\begin{aligned}
u_{2}= & 4.241+0.01830 u_{t}-1.106 X_{b a 1}+0.190 X_{b a 2}+1.925 X_{b a 3}-0.00601 A S_{1}+0.004379 A S_{2} \\
& -0.00686 A S_{3}-0.000058 T_{\text {out }}+0.00397 C_{g h}+0.1013 C_{g}+0.1261 C_{s}-0.000036 u_{t}{ }^{*} A S_{1} \\
& +0.000030 u_{t}{ }^{*} A S_{2}-0.000014 u_{t}{ }^{*} A S_{3}+0.000405 u_{t}{ }^{*} C_{g h}+0.000587 u_{t}{ }^{*} C_{g}-0.001144 u_{t}{ }^{*} C_{s} \\
& +0.000131 X_{b a 1}{ }^{*} T_{\text {out }}-0.327 X_{b a 2}{ }^{*} C_{s}-0.2243 X_{b a 3}{ }^{*} C_{g}+0.000012 A S_{1}{ }^{*} A S_{3} \\
& -0.000404 A S_{1}{ }^{*} C_{g}+0.000670 A S_{1}{ }^{*} C_{s}+0.000101 A S_{2}{ }^{*} C_{g}-0.000218 A S_{2}{ }^{*} C_{s} \\
& +0.000105 A S_{3}{ }^{*} C_{g}+0.000001 T_{\text {out }}{ }^{*} C_{g}-0.00676 C_{g h}{ }^{*} C_{s}-0.007003 C_{g}{ }^{*} C_{s}
\end{aligned}
$$

\begin{tabular}{|c|c|c|c|c|c|c|}
\hline Term & Effect & Coef & SE Coef & T-Value & $p$-Value & VIF \\
\hline Constant & & 4.03383 & 0.00598 & 674.32 & 0.000 & \\
\hline ut & 0.80109 & 0.40055 & 0.00598 & 66.96 & 0.000 & 1.00 \\
\hline Xba1 & -0.01922 & -0.00961 & 0.00598 & -1.61 & 0.111 & 1.00 \\
\hline $\mathrm{Xba} 2$ & -0.04359 & -0.02180 & 0.00598 & -3.64 & 0.000 & 1.00 \\
\hline Xba3 & 0.02766 & 0.01383 & 0.00598 & 2.31 & 0.023 & 1.00 \\
\hline AS1 & -0.25172 & -0.12586 & 0.00598 & -21.04 & 0.000 & 1.00 \\
\hline AS2 & 0.43266 & 0.21633 & 0.00598 & 36.16 & 0.000 & 1.00 \\
\hline AS3 & -0.16828 & -0.08414 & 0.00598 & -14.07 & 0.000 & 1.00 \\
\hline Tout & -0.08484 & -0.04242 & 0.00598 & -7.09 & 0.000 & 1.00 \\
\hline Cgh & 0.03328 & 0.01664 & 0.00598 & 2.78 & 0.006 & 1.00 \\
\hline $\mathrm{Cg}$ & -0.27141 & -0.13570 & 0.00598 & -22.68 & 0.000 & 1.00 \\
\hline Cs & 0.17766 & 0.08883 & 0.00598 & 14.85 & 0.000 & 1.00 \\
\hline $\mathrm{ut}^{*} \mathrm{AS} 1$ & -0.08766 & -0.04383 & 0.00598 & -7.33 & 0.000 & 1.00 \\
\hline $\mathrm{ut}^{*} \mathrm{AS} 2$ & 0.07359 & 0.03680 & 0.00598 & 6.15 & 0.000 & 1.00 \\
\hline $\mathrm{ut}^{*} \mathrm{AS} 3$ & -0.03422 & -0.01711 & 0.00598 & -2.86 & 0.005 & 1.00 \\
\hline $\mathrm{ut}^{*} \mathrm{Cgh}$ & 0.05672 & 0.02836 & 0.00598 & 4.74 & 0.000 & 1.00 \\
\hline $\mathrm{ut}^{*} \mathrm{Cg}$ & 0.14391 & 0.07195 & 0.00598 & 12.03 & 0.000 & 1.00 \\
\hline $\mathrm{ut}^{*} \mathrm{Cs}$ & -0.14016 & -0.07008 & 0.00598 & -11.71 & 0.000 & 1.00 \\
\hline Xba1*Tout & 0.02953 & 0.01477 & 0.00598 & 2.47 & 0.015 & 1.00 \\
\hline $\mathrm{Xba}{ }^{*} \mathrm{Cs}$ & -0.02859 & -0.01430 & 0.00598 & -2.39 & 0.019 & 1.00 \\
\hline $\mathrm{Xba}^{*} \mathrm{Cg}$ & -0.03141 & -0.01570 & 0.00598 & -2.63 & 0.010 & 1.00 \\
\hline AS1*AS3 & 0.03047 & 0.01523 & 0.00598 & 2.55 & 0.012 & 1.00 \\
\hline $\mathrm{AS} 1{ }^{*} \mathrm{Cg}$ & -0.09891 & -0.04945 & 0.00598 & -8.27 & 0.000 & 1.00 \\
\hline $\mathrm{AS} 1{ }^{*} \mathrm{Cs}$ & 0.08203 & 0.04102 & 0.00598 & 6.86 & 0.000 & 1.00 \\
\hline $\mathrm{AS} 2{ }^{*} \mathrm{Cg}$ & 0.02484 & 0.01242 & 0.00598 & 2.08 & 0.040 & 1.00 \\
\hline $\mathrm{AS} 2 * \mathrm{Cs}$ & -0.02672 & -0.01336 & 0.00598 & -2.23 & 0.028 & 1.00 \\
\hline $\mathrm{AS3}^{*} \mathrm{Cg}$ & 0.02578 & 0.01289 & 0.00598 & 2.15 & 0.034 & 1.00 \\
\hline Tout ${ }^{*} \mathrm{Cg}$ & 0.03234 & 0.01617 & 0.00598 & 2.70 & 0.008 & 1.00 \\
\hline $\mathrm{Cgh}^{*} \mathrm{Cs}$ & -0.04734 & -0.02367 & 0.00598 & -3.96 & 0.000 & 1.00 \\
\hline $\mathrm{Cg}^{*} \mathrm{Cs}$ & -0.08578 & -0.04289 & 0.00598 & -7.17 & 0.000 & 1.00 \\
\hline \multicolumn{7}{|c|}{ Coded Coefficients. } \\
\hline$S$ & & R-sq & \multicolumn{2}{|c|}{ R-sq(adj) } & \multicolumn{2}{|c|}{ R-sq(pred) } \\
\hline 0.0676794 & & $98.77 \%$ & \multicolumn{2}{|c|}{$98.41 \%$} & \multicolumn{2}{|c|}{$97.90 \%$} \\
\hline
\end{tabular}

It can be said that the experimental data are greatly consistent with the proposed model when the minimum value of $\mathrm{R}$-square is approximately $98 \%$ (all of them are more than $98 \%$ ).

Table 4. Estimated Effects and Coefficients for $u_{2}$.

In the case of $u_{3}$ response, the results obtained from regression process show the difference from those of $u_{2}$ response. Indeed, $u_{t}$ and $X_{b a 2}$ have no influence on the response, moreover, only eight interactions between input parameters have impact on it (cf. Table 5). It is observed that the factors of $B$, $\mathrm{D}, \mathrm{E}$, and $\mathrm{H}$ have $p$-value of $0.078,0.184,0.146$, and 0.052 respectively, larger than significance $\alpha(0.05)$. Hence, these parameters have little influence on the $u_{3}$ response. However, the interactions of $\mathrm{BH}, \mathrm{BL}$, DG, EG, and EK have $p$-value inferior to $\alpha$. For this reason, they strongly influence the response of $u_{3}$. 
The regression equation of this response can be presented as following model (Regression Equation in Uncoded Units):

$$
\begin{aligned}
u_{3}= & -16.99+0.19 X_{b a 1}+29.9 X_{b a 3}+0.01838 A S_{1}-0.005652 A S_{2}+0.0599 A S_{3} \\
& +0.000197 T_{o u t}-0.1537 C_{g h}-0.079 C_{g}+0.072 C_{s}-0.000575 X_{b a 1}{ }^{*} T_{\text {out }} \\
& +1.404 X_{b a 1}{ }^{*} C_{s}-0.0737 X_{b a 3}{ }^{*} A S_{3}-0.000053 A S_{1}{ }^{*} A S_{3}+0.000524 A S_{1}{ }^{*} C_{g} \\
& -0.000528 A S_{3}{ }^{*} C_{g}+0.01440 C_{g h}{ }^{*} C_{g}-0.03934 C_{g}{ }^{*} C_{s}
\end{aligned}
$$

\begin{tabular}{|c|c|c|c|c|c|c|}
\hline Term & Effect & Coef & SE Coef & T-Value & $p$-Value & VIF \\
\hline Constant & & 4.2002 & 0.0224 & 187.27 & 0.000 & \\
\hline Xba1 & 0.0797 & 0.0398 & 0.0224 & 1.78 & 0.078 & 1.00 \\
\hline Xba3 & 0.0600 & 0.0300 & 0.0224 & 1.34 & 0.184 & 1.00 \\
\hline AS1 & 0.0656 & 0.0328 & 0.0224 & 1.46 & 0.146 & 1.00 \\
\hline AS2 & -0.3956 & -0.1978 & 0.0224 & -8.82 & 0.000 & 1.00 \\
\hline AS3 & 0.6103 & 0.3052 & 0.0224 & 13.61 & 0.000 & 1.00 \\
\hline Tout & 0.0881 & 0.0441 & 0.0224 & 1.96 & 0.052 & 1.00 \\
\hline Cgh & -0.2981 & -0.1491 & 0.0224 & -6.65 & 0.000 & 1.00 \\
\hline $\mathrm{Cg}$ & -1.1550 & -0.5775 & 0.0224 & -25.75 & 0.000 & 1.00 \\
\hline $\mathrm{Cs}$ & 1.0922 & 0.5461 & 0.0224 & 24.35 & 0.000 & 1.00 \\
\hline Xba1*Tout & -0.1294 & -0.0647 & 0.0224 & -2.88 & 0.005 & 1.00 \\
\hline $\mathrm{Xba} 1^{*} \mathrm{Cs}$ & 0.1228 & 0.0614 & 0.0224 & 2.74 & 0.007 & 1.00 \\
\hline $\mathrm{Xba}^{*} \mathrm{AS} 3$ & -0.1031 & -0.0516 & 0.0224 & -2.30 & 0.023 & 1.00 \\
\hline AS1*AS3 & -0.1294 & -0.0647 & 0.0224 & -2.88 & 0.005 & 1.00 \\
\hline $\mathrm{AS}^{*} \mathrm{Cg}$ & 0.1284 & 0.0642 & 0.0224 & 2.86 & 0.005 & 1.00 \\
\hline $\mathrm{AS3}^{*} \mathrm{Cg}$ & -0.1294 & -0.0647 & 0.0224 & -2.88 & 0.005 & 1.00 \\
\hline $\mathrm{Cgh}^{*} \mathrm{Cg}$ & 0.2016 & 0.1008 & 0.0224 & 4.49 & 0.000 & 1.00 \\
\hline $\mathrm{Cg} * \mathrm{Cs}$ & -0.4819 & -0.2409 & 0.0224 & -10.74 & 0.000 & 1.00 \\
\hline \multicolumn{7}{|c|}{ Coded Coefficients. } \\
\hline S & & R-sq & \multicolumn{2}{|c|}{ R-sq(adj) } & \multicolumn{2}{|c|}{ R-sq(pred) } \\
\hline 0.253752 & & $94.10 \%$ & \multicolumn{2}{|c|}{$93.19 \%$} & \multicolumn{2}{|c|}{$92.02 \%$} \\
\hline
\end{tabular}

Table 5. Estimated effects and coefficients for $u_{3}$.

The results in Table 5 also report that the experimental data are highly consistent with the proposed model when the minimum value of R-square approximately $92.02 \%$ (all of them are more than $92.02 \%$ ). However, this is less reliable when compared to that of $u_{2}$ response.

Based on previous analysis, it can be said that the proposed models of $u_{2}$ and $u_{3}$ can be utilized to get the optimum gear ratio of the second and third stages. As a consequence, the optimum gear ratio of the first stage can be obtained by $u_{1}=u_{t} /\left(u_{2} \cdot u_{3}\right)$.

\subsection{Analysis of Variance-ANOVA}

In order to quantitatively conclude the impact of each parameters and their interactions on the responses, Analysis of Variance is necessary. Table 5 reveals the Analysis of Variance in case of $u_{2}$ response. It is observed that F-values of some parameters of $\mathrm{A}, \mathrm{F}, \mathrm{K}, \mathrm{E}, \mathrm{L}, \mathrm{G}, \mathrm{AK}, \mathrm{AL}, \mathrm{EK}, \mathrm{AE}, \mathrm{KL}, \mathrm{H}$, $\mathrm{EL}, \mathrm{AF}, \mathrm{AJ}$, and JL exhibit the F-value higher than 50 , and it can be concluded that these parameters have static significance. The R-square value in this case is high when the lowest $\mathrm{R}$-square approaches $92 \%$. In a similar way, we can also identify the high F-value of parameters in case of the $u_{3}$ response, such as K, L, G, KL, F, and J. the lowest value of R-square reaches $92 \%$. 


\subsection{Validation of Proposed Model}

The estimation of errors resulting from the difference between experiments and model of $u_{2}$ is qualitatively described in Figure 7. From the Normal Probability Plot, it is observed that the contribution of errors is similar to normal distribution. The Versus fits graph discloses that the relation between residual and fitted value of model is random. Moreover, the Versus Order also exhibits the random relationship between residual and order of data point. The identical tendency is also noted when comparing experiments and proposed model in case of $u_{3}$ response. The observed phenomena given by the graphs one more time show the reliability of the proposed model which is highly fitted for the experiments.
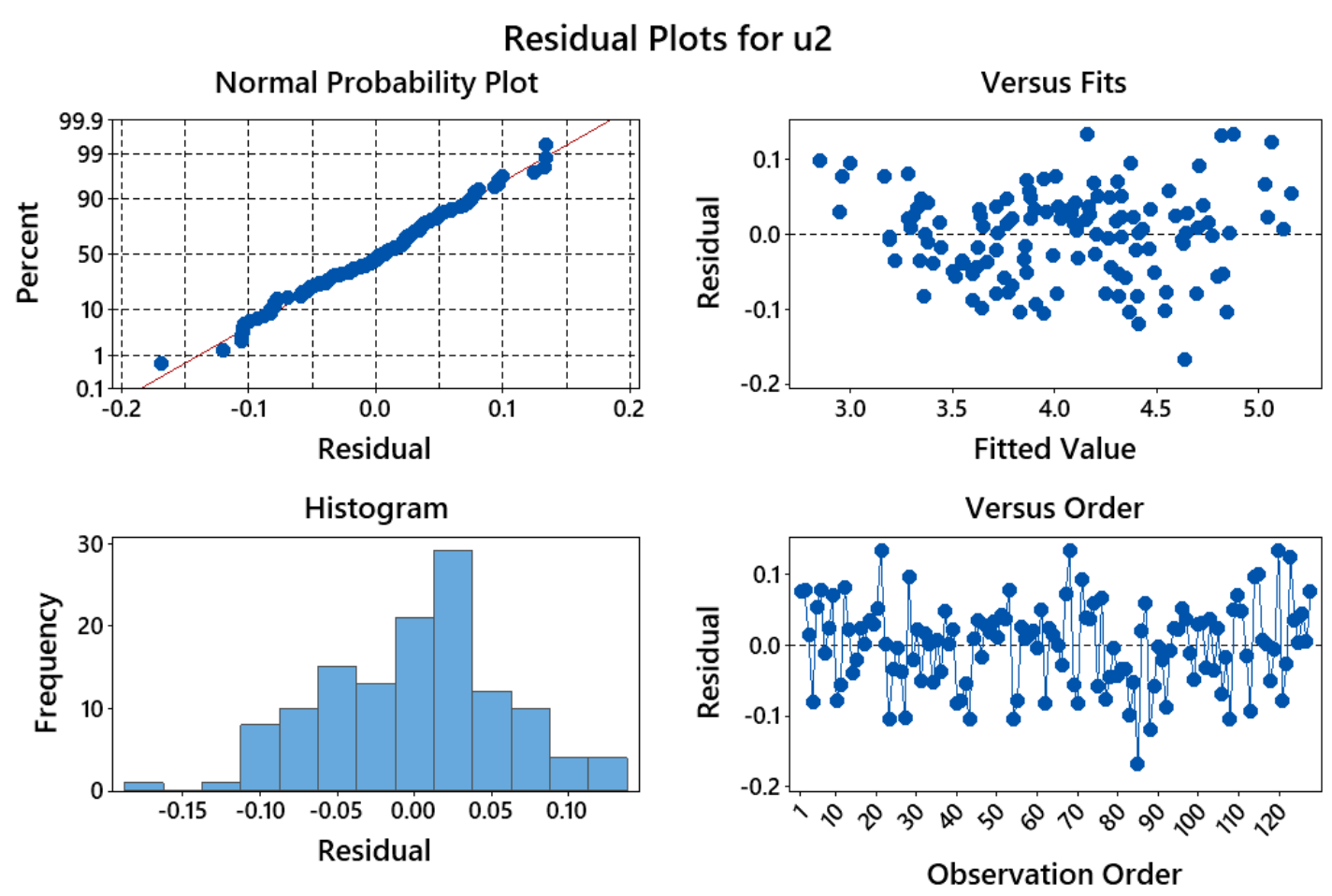

Figure 7. Graphs estimating errors between experiments and model of $u_{2}$.

Another way to validate the approximation of data is probability plot exhibited in Figure 8 . The Anderson-Darling test in Minitab@19 which is a statistical test to validate the data set come from a specific distribution, e.g., the normal distribution or not. In this way, the data set is representative by blue points. There are three straight lines in the plot where the middle line presents the probability of normal distribution, while two lines in the left and the right refer to limiting boundary with significance of $95 \%$. It is observed that all data set for both case of $u_{2}$ and $u_{3}$ are sited inside two limiting line when the $p$-value of 0.289 and 0.097 are greater than $\alpha$ value of 0.05 . This indicates that the data set follows the distribution. 


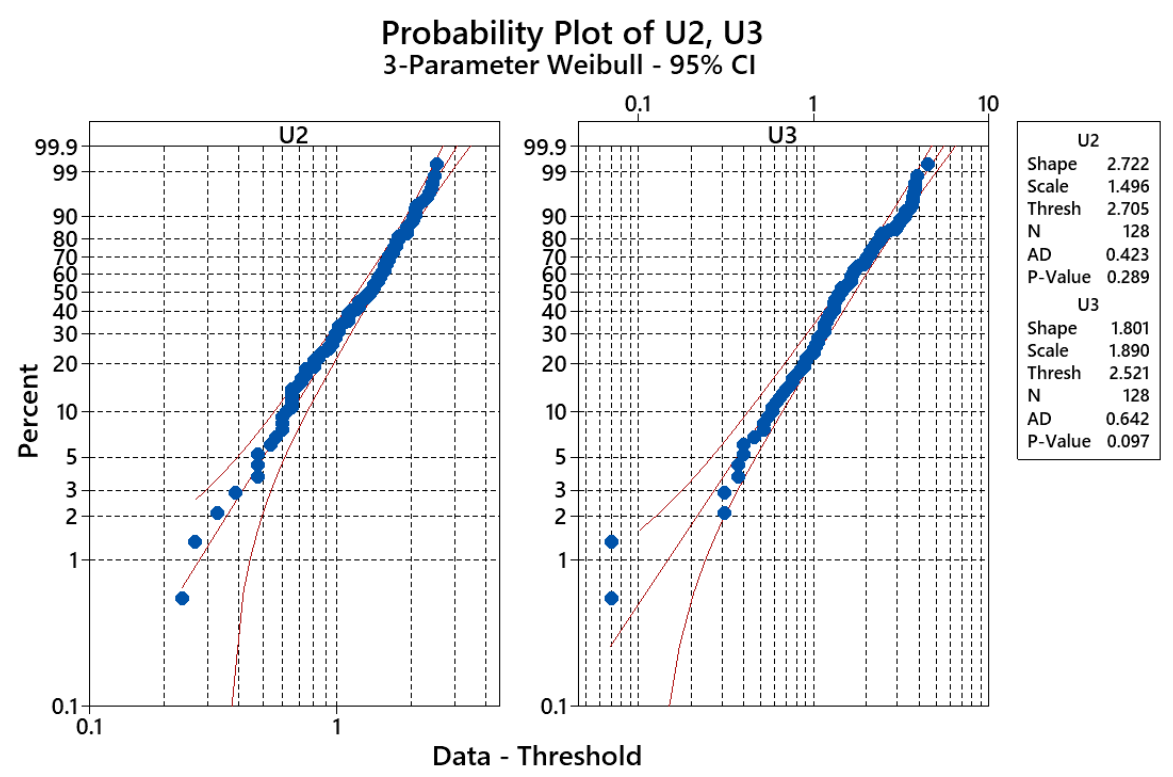

Figure 8. Probability plot of the validity of proposed model for the response of $u_{2}$ and $u_{3}$.

\section{Conclusions}

The influence of main design parameters on the optimum partial gear ratios for three-stage helical gearboxes was conducted. The optimum partial gear ratios are derived from the results of optimization problem for getting minimum gearbox cost. This is the first result appearing in scientific publications. To solve the optimum problem, a computer program was built, while a plan of simulation experiments was designed and carried out. The influences of eleven input parameters and their interactions on the output response of $u_{2}$ and $u_{3}$ were investigated. The input parameters include total gearbox ratio, coefficient of wheel face width of stage 1 , coefficient of wheel face width of stage 2 , coefficient of wheel face width of stage 3 , allowable contact stress of stage 1 , allowable contact stress of stage 2 , allowable contact stress of stage 3, output torque, cost of gearbox housing, cost of gears, and cost of shafts. The following conclusion can be made:

$\checkmark \quad$ The influence of input parameters and their interactions on $u_{2}$ response is different from those of $u_{3}$ response. The ANOVA results showed that the parameters of $A, F, K, E, L, G, A K, A L, E K, A E$, $\mathrm{KL}, \mathrm{H}, \mathrm{EL}, \mathrm{AF}, \mathrm{AJ}$, and JL have significant influence on $u_{2}$ response (R-square value approaching $98 \%$ ), while the corresponding to be the parameters of $K, L, G, K L, F$, and J in case of $u_{3}$ (R-square of $92 \%)$.

$\checkmark \quad$ The parameters having insignificant influence were eliminated, inversely, the others that had strong influence would be considered for deeper experiments.

$\checkmark \quad$ The proposed models of both $u_{2}$ and $u_{3}$ responses are highly consistent to experimental data. The reliability of the models is validated. It can be said that the proposed models can be applied to optimize the costs of gearbox.

Author Contributions: All authors discussed the original idea. V.-C.N., A.-T.L., N.-G.T., and N.-P.V. conducted the optimization problem. On the other hand, D.-N.N. wrote this manuscript with support from T.-D.B., T.-D.B., T.-H.T., H.-L.N., and N.-P.V. In addition, A.-T.L., N.-G.T., and N.-P.V. carried out the figures and experimental analysis. All authors provided critical feedback and helped shape the research, analysis, and manuscript. Finally, N.-P.V. supervised this work and revised the article. All authors have read and agreed to the published version of the manuscript.

Funding: This research received no external funding.

Acknowledgments: The authors gratefully acknowledge Thai Nguyen University of Technology for supporting this work.

Conflicts of Interest: The authors state no conflict of interest. 
Appendix A

\begin{tabular}{|c|c|c|c|c|c|c|c|c|c|c|c|c|c|c|c|}
\hline Run Order & CenterPt & Blocks & $u_{t}$ & $X_{b a 1}$ & $X_{b a 2}$ & $X_{b a 3}$ & $A S_{1}$ & $A S_{2}$ & $A S_{3}$ & $T_{\text {out }}$ & $C_{g h}$ & $C_{g}$ & $C_{s}$ & $u_{2}$ & $u_{3}$ \\
\hline 1 & 1 & 1 & 30 & 0.35 & 0.38 & 0.4 & 350 & 420 & 350 & 1000 & 1 & 2 & 1.5 & 4.02 & 3.64 \\
\hline 2 & 1 & 1 & 100 & 0.35 & 0.33 & 0.36 & 420 & 350 & 420 & 1000 & 5 & 2 & 1.5 & 4.08 & 4.24 \\
\hline 3 & 1 & 1 & 100 & 0.3 & 0.33 & 0.4 & 420 & 350 & 350 & 1000 & 5 & 9 & 5 & 4.11 & 3.73 \\
\hline 4 & 1 & 1 & 30 & 0.35 & 0.33 & 0.4 & 350 & 350 & 350 & 1000 & 5 & 2 & 1.5 & 3.63 & 3.58 \\
\hline 5 & 1 & 1 & 100 & 0.3 & 0.33 & 0.36 & 350 & 420 & 350 & 1000 & 5 & 9 & 1.5 & 5.22 & 2.59 \\
\hline 6 & 1 & 1 & 30 & 0.35 & 0.38 & 0.4 & 420 & 350 & 350 & 10000 & 5 & 9 & 1.5 & 3.03 & 3.28 \\
\hline 7 & 1 & 1 & 100 & 0.3 & 0.33 & 0.4 & 420 & 420 & 420 & 10000 & 5 & 2 & 5 & 4.62 & 5.14 \\
\hline 8 & 1 & 1 & 100 & 0.35 & 0.38 & 0.36 & 350 & 420 & 350 & 1000 & 5 & 2 & 1.5 & 5.07 & 3.25 \\
\hline 9 & 1 & 1 & 30 & 0.3 & 0.33 & 0.36 & 350 & 420 & 350 & 10000 & 5 & 2 & 5 & 4.26 & 4.63 \\
\hline 10 & 1 & 1 & 100 & 0.3 & 0.38 & 0.4 & 420 & 350 & 350 & 10000 & 1 & 2 & 1.5 & 3.93 & 4.75 \\
\hline 11 & 1 & 1 & 30 & 0.3 & 0.38 & 0.36 & 420 & 350 & 350 & 1000 & 5 & 2 & 1.5 & 3.45 & 3.58 \\
\hline 12 & 1 & 1 & 30 & 0.3 & 0.38 & 0.4 & 350 & 350 & 420 & 10000 & 5 & 9 & 5 & 3.36 & 4.3 \\
\hline 13 & 1 & 1 & 30 & 0.3 & 0.38 & 0.36 & 420 & 420 & 420 & 10000 & 5 & 9 & 1.5 & 3.3 & 3.37 \\
\hline 14 & 1 & 1 & 30 & 0.3 & 0.38 & 0.4 & 350 & 350 & 350 & 1000 & 5 & 9 & 1.5 & 3.36 & 3.07 \\
\hline 15 & 1 & 1 & 100 & 0.35 & 0.38 & 0.4 & 350 & 350 & 350 & 1000 & 1 & 2 & 1.5 & 4.44 & 3.67 \\
\hline 16 & 1 & 1 & 100 & 0.35 & 0.33 & 0.36 & 420 & 350 & 350 & 10000 & 5 & 2 & 5 & 4.35 & 4.69 \\
\hline 17 & 1 & 1 & 30 & 0.35 & 0.38 & 0.36 & 350 & 350 & 420 & 1000 & 5 & 2 & 5 & 3.72 & 6.16 \\
\hline 18 & 1 & 1 & 100 & 0.3 & 0.33 & 0.36 & 420 & 350 & 420 & 10000 & 1 & 2 & 5 & 4.11 & 6.28 \\
\hline 19 & 1 & 1 & 30 & 0.3 & 0.33 & 0.36 & 420 & 350 & 420 & 1000 & 1 & 9 & 1.5 & 2.97 & 3.79 \\
\hline 20 & 1 & 1 & 100 & 0.3 & 0.38 & 0.4 & 420 & 350 & 420 & 1000 & 1 & 2 & 5 & 4.26 & 6.04 \\
\hline 21 & 1 & 1 & 100 & 0.3 & 0.33 & 0.4 & 420 & 420 & 350 & 1000 & 5 & 2 & 1.5 & 4.95 & 2.89 \\
\hline 22 & 1 & 1 & 100 & 0.35 & 0.33 & 0.36 & 420 & 420 & 420 & 1000 & 5 & 9 & 5 & 4.41 & 3.91 \\
\hline 23 & 1 & 1 & 100 & 0.3 & 0.33 & 0.4 & 420 & 350 & 420 & 10000 & 5 & 9 & 1.5 & 3.72 & 4.15 \\
\hline 24 & 1 & 1 & 30 & 0.3 & 0.33 & 0.4 & 350 & 350 & 420 & 1000 & 1 & 2 & 1.5 & 3.51 & 4.63 \\
\hline 25 & 1 & 1 & 30 & 0.35 & 0.33 & 0.36 & 350 & 350 & 420 & 10000 & 1 & 9 & 1.5 & 3.18 & 3.67 \\
\hline 26 & 1 & 1 & 30 & 0.3 & 0.38 & 0.36 & 420 & 350 & 420 & 10000 & 5 & 2 & 5 & 3.63 & 6.43 \\
\hline 27 & 1 & 1 & 100 & 0.35 & 0.33 & 0.36 & 420 & 420 & 350 & 10000 & 5 & 9 & 1.5 & 4.44 & 3.13 \\
\hline 28 & 1 & 1 & 30 & 0.35 & 0.33 & 0.36 & 420 & 350 & 350 & 1000 & 5 & 9 & 1.5 & 3.09 & 3.16 \\
\hline 29 & 1 & 1 & 100 & 0.35 & 0.38 & 0.4 & 420 & 350 & 350 & 1000 & 5 & 2 & 5 & 4.38 & 5.65 \\
\hline 30 & 1 & 1 & 100 & 0.3 & 0.38 & 0.4 & 350 & 350 & 420 & 1000 & 5 & 2 & 1.5 & 4.41 & 4.15 \\
\hline 31 & 1 & 1 & 30 & 0.3 & 0.33 & 0.4 & 350 & 420 & 420 & 1000 & 1 & 9 & 5 & 3.81 & 4.06 \\
\hline 32 & 1 & 1 & 100 & 0.35 & 0.38 & 0.36 & 420 & 420 & 350 & 1000 & 1 & 2 & 5 & 4.77 & 4.99 \\
\hline 33 & 1 & 1 & 30 & 0.3 & 0.33 & 0.4 & 350 & 420 & 350 & 10000 & 1 & 9 & 1.5 & 3.72 & 2.83 \\
\hline 34 & 1 & 1 & 100 & 0.35 & 0.38 & 0.4 & 350 & 420 & 350 & 1000 & 1 & 9 & 5 & 4.77 & 3.97 \\
\hline 35 & 1 & 1 & 100 & 0.35 & 0.33 & 0.4 & 420 & 420 & 420 & 1000 & 1 & 2 & 1.5 & 4.44 & 4.3 \\
\hline 36 & 1 & 1 & 30 & 0.35 & 0.38 & 0.36 & 350 & 350 & 350 & 10000 & 5 & 2 & 1.5 & 3.51 & 3.82 \\
\hline 37 & 1 & 1 & 30 & 0.35 & 0.33 & 0.4 & 350 & 350 & 420 & 10000 & 5 & 2 & 5 & 3.81 & 6.22 \\
\hline 38 & 1 & 1 & 100 & 0.35 & 0.33 & 0.4 & 350 & 420 & 420 & 1000 & 5 & 2 & 5 & 4.86 & 5.53 \\
\hline 39 & 1 & 1 & 30 & 0.35 & 0.38 & 0.36 & 420 & 350 & 350 & 10000 & 1 & 2 & 5 & 3.9 & 5.5 \\
\hline 40 & 1 & 1 & 100 & 0.3 & 0.38 & 0.4 & 420 & 420 & 420 & 1000 & 1 & 9 & 1.5 & 4.23 & 3.76 \\
\hline 41 & 1 & 1 & 100 & 0.3 & 0.38 & 0.36 & 350 & 420 & 420 & 1000 & 1 & 2 & 1.5 & 4.62 & 4.51 \\
\hline 42 & 1 & 1 & 100 & 0.35 & 0.38 & 0.36 & 350 & 350 & 420 & 10000 & 5 & 9 & 1.5 & 4.26 & 3.52 \\
\hline 43 & 1 & 1 & 30 & 0.3 & 0.33 & 0.4 & 420 & 350 & 420 & 1000 & 5 & 2 & 5 & 3.84 & 5.65 \\
\hline 44 & 1 & 1 & 100 & 0.3 & 0.33 & 0.36 & 350 & 420 & 420 & 10000 & 5 & 9 & 5 & 4.71 & 3.82 \\
\hline 45 & 1 & 1 & 100 & 0.3 & 0.38 & 0.36 & 420 & 350 & 420 & 1000 & 5 & 9 & 1.5 & 3.93 & 3.46 \\
\hline 46 & 1 & 1 & 30 & 0.3 & 0.33 & 0.36 & 350 & 350 & 420 & 1000 & 5 & 9 & 5 & 3.42 & 4.12 \\
\hline 47 & 1 & 1 & 100 & 0.3 & 0.33 & 0.36 & 350 & 350 & 350 & 1000 & 5 & 2 & 5 & 4.68 & 4.51 \\
\hline 48 & 1 & 1 & 100 & 0.35 & 0.33 & 0.36 & 350 & 350 & 420 & 1000 & 1 & 2 & 5 & 4.32 & 7.03 \\
\hline 49 & 1 & 1 & 100 & 0.3 & 0.33 & 0.4 & 350 & 350 & 350 & 1000 & 1 & 9 & 1.5 & 4.5 & 2.92 \\
\hline 50 & 1 & 1 & 30 & 0.3 & 0.38 & 0.36 & 420 & 420 & 350 & 1000 & 5 & 9 & 5 & 3.66 & 3.76 \\
\hline 51 & 1 & 1 & 30 & 0.35 & 0.33 & 0.4 & 420 & 350 & 350 & 1000 & 1 & 2 & 5 & 4.14 & 5.86 \\
\hline 52 & 1 & 1 & 30 & 0.3 & 0.33 & 0.4 & 350 & 350 & 350 & 10000 & 1 & 2 & 5 & 4.05 & 6.16 \\
\hline 53 & 1 & 1 & 30 & 0.35 & 0.38 & 0.4 & 420 & 350 & 420 & 1000 & 5 & 9 & 5 & 3.24 & 4.63 \\
\hline 54 & 1 & 1 & 100 & 0.35 & 0.38 & 0.36 & 350 & 350 & 350 & 1000 & 5 & 9 & 5 & 4.26 & 4.15 \\
\hline 55 & 1 & 1 & 30 & 0.3 & 0.38 & 0.4 & 350 & 420 & 420 & 10000 & 5 & 2 & 1.5 & 3.69 & 4.45 \\
\hline 56 & 1 & 1 & 30 & 0.35 & 0.38 & 0.4 & 420 & 420 & 350 & 10000 & 5 & 2 & 5 & 4.2 & 4.81 \\
\hline 57 & 1 & 1 & 30 & 0.35 & 0.33 & 0.4 & 420 & 350 & 420 & 10000 & 1 & 2 & 1.5 & 3.3 & 4.87 \\
\hline 58 & 1 & 1 & 30 & 0.3 & 0.33 & 0.4 & 420 & 350 & 350 & 10000 & 5 & 2 & 1.5 & 3.45 & 3.58 \\
\hline
\end{tabular}




\begin{tabular}{|c|c|c|c|c|c|c|c|c|c|c|c|c|c|c|c|}
\hline Run Order & CenterPt & Blocks & $u_{t}$ & $X_{b a 1}$ & $X_{b a 2}$ & $X_{b a 3}$ & $A S_{1}$ & $A S_{2}$ & $A S_{3}$ & $T_{\text {out }}$ & $C_{g h}$ & $C_{g}$ & $C_{s}$ & $u_{2}$ & $u_{3}$ \\
\hline 59 & 1 & 1 & 30 & 0.35 & 0.38 & 0.36 & 350 & 420 & 350 & 10000 & 5 & 9 & 5 & 3.81 & 3.52 \\
\hline 60 & 1 & 1 & 30 & 0.3 & 0.38 & 0.4 & 350 & 420 & 350 & 1000 & 5 & 2 & 5 & 4.32 & 4.54 \\
\hline 61 & 1 & 1 & 30 & 0.35 & 0.33 & 0.4 & 350 & 420 & 350 & 1000 & 5 & 9 & 5 & 3.93 & 3.43 \\
\hline 62 & 1 & 1 & 100 & 0.3 & 0.38 & 0.4 & 420 & 420 & 350 & 10000 & 1 & 9 & 5 & 4.32 & 4.15 \\
\hline 63 & 1 & 1 & 100 & 0.3 & 0.38 & 0.36 & 420 & 420 & 350 & 10000 & 5 & 2 & 1.5 & 4.62 & 3.28 \\
\hline 64 & 1 & 1 & 100 & 0.35 & 0.38 & 0.36 & 420 & 350 & 420 & 10000 & 1 & 9 & 5 & 3.78 & 4.48 \\
\hline 65 & 1 & 1 & 100 & 0.35 & 0.38 & 0.4 & 350 & 350 & 420 & 10000 & 1 & 2 & 5 & 4.2 & 6.34 \\
\hline 66 & 1 & 1 & 30 & 0.35 & 0.33 & 0.36 & 350 & 420 & 350 & 1000 & 1 & 2 & 1.5 & 3.96 & 3.85 \\
\hline 67 & 1 & 1 & 100 & 0.35 & 0.33 & 0.4 & 420 & 350 & 420 & 1000 & 1 & 9 & 5 & 3.93 & 4.18 \\
\hline 68 & 1 & 1 & 30 & 0.35 & 0.38 & 0.4 & 350 & 420 & 420 & 1000 & 1 & 2 & 5 & 4.29 & 5.86 \\
\hline 69 & 1 & 1 & 100 & 0.35 & 0.33 & 0.4 & 420 & 420 & 350 & 10000 & 1 & 2 & 5 & 4.74 & 5.59 \\
\hline 70 & 1 & 1 & 30 & 0.3 & 0.33 & 0.36 & 420 & 350 & 350 & 10000 & 1 & 9 & 5 & 3.27 & 3.91 \\
\hline 71 & 1 & 1 & 100 & 0.3 & 0.38 & 0.4 & 350 & 420 & 420 & 1000 & 5 & 9 & 5 & 4.8 & 3.82 \\
\hline 72 & 1 & 1 & 100 & 0.35 & 0.38 & 0.4 & 350 & 420 & 420 & 10000 & 1 & 9 & 1.5 & 4.77 & 3.4 \\
\hline 73 & 1 & 1 & 100 & 0.3 & 0.38 & 0.36 & 350 & 350 & 420 & 1000 & 1 & 9 & 5 & 4.2 & 4.15 \\
\hline 74 & 1 & 1 & 30 & 0.3 & 0.33 & 0.36 & 350 & 420 & 420 & 1000 & 5 & 2 & 1.5 & 3.93 & 3.34 \\
\hline 75 & 1 & 1 & 30 & 0.35 & 0.38 & 0.4 & 420 & 420 & 420 & 1000 & 5 & 2 & 1.5 & 3.69 & 3.61 \\
\hline 76 & 1 & 1 & 100 & 0.35 & 0.33 & 0.4 & 350 & 420 & 350 & 10000 & 5 & 2 & 1.5 & 5.1 & 3.1 \\
\hline 77 & 1 & 1 & 100 & 0.35 & 0.38 & 0.4 & 420 & 420 & 350 & 1000 & 5 & 9 & 1.5 & 4.47 & 3.19 \\
\hline 78 & 1 & 1 & 30 & 0.35 & 0.33 & 0.36 & 420 & 420 & 350 & 1000 & 5 & 2 & 5 & 4.23 & 4.87 \\
\hline 79 & 1 & 1 & 30 & 0.3 & 0.33 & 0.36 & 420 & 420 & 420 & 1000 & 1 & 2 & 5 & 4.26 & 5.86 \\
\hline 80 & 1 & 1 & 30 & 0.35 & 0.33 & 0.4 & 350 & 420 & 420 & 10000 & 5 & 9 & 1.5 & 3.57 & 3.4 \\
\hline 81 & 1 & 1 & 100 & 0.35 & 0.33 & 0.4 & 420 & 350 & 350 & 10000 & 1 & 9 & 1.5 & 3.81 & 3.7 \\
\hline 82 & 1 & 1 & 30 & 0.35 & 0.33 & 0.36 & 420 & 350 & 420 & 10000 & 5 & 9 & 5 & 3.18 & 4.57 \\
\hline 83 & 1 & 1 & 30 & 0.35 & 0.33 & 0.4 & 420 & 420 & 420 & 10000 & 1 & 9 & 5 & 3.54 & 4.03 \\
\hline 84 & 1 & 1 & 30 & 0.35 & 0.38 & 0.36 & 420 & 420 & 420 & 1000 & 1 & 9 & 5 & 3.54 & 4.36 \\
\hline 85 & 1 & 1 & 100 & 0.35 & 0.38 & 0.36 & 350 & 420 & 420 & 10000 & 5 & 2 & 5 & 4.47 & 6.31 \\
\hline 86 & 1 & 1 & 100 & 0.3 & 0.33 & 0.4 & 350 & 350 & 420 & 10000 & 1 & 9 & 5 & 4.17 & 4.24 \\
\hline 87 & 1 & 1 & 100 & 0.3 & 0.33 & 0.36 & 420 & 420 & 350 & 1000 & 1 & 9 & 5 & 4.62 & 3.22 \\
\hline 88 & 1 & 1 & 100 & 0.35 & 0.33 & 0.4 & 350 & 350 & 350 & 10000 & 5 & 9 & 5 & 4.29 & 3.97 \\
\hline 89 & 1 & 1 & 100 & 0.35 & 0.33 & 0.4 & 350 & 350 & 420 & 1000 & 5 & 9 & 1.5 & 4.29 & 3.55 \\
\hline 90 & 1 & 1 & 100 & 0.35 & 0.33 & 0.36 & 350 & 420 & 420 & 1000 & 1 & 9 & 1.5 & 4.77 & 3.43 \\
\hline 91 & 1 & 1 & 30 & 0.3 & 0.38 & 0.36 & 350 & 420 & 420 & 10000 & 1 & 9 & 5 & 3.69 & 3.97 \\
\hline 92 & 1 & 1 & 30 & 0.35 & 0.33 & 0.36 & 350 & 350 & 350 & 1000 & 1 & 9 & 5 & 3.51 & 3.73 \\
\hline 93 & 1 & 1 & 30 & 0.35 & 0.38 & 0.4 & 350 & 350 & 420 & 1000 & 1 & 9 & 1.5 & 3.18 & 3.82 \\
\hline 94 & 1 & 1 & 30 & 0.3 & 0.33 & 0.4 & 420 & 420 & 350 & 10000 & 5 & 9 & 5 & 3.66 & 3.52 \\
\hline 95 & 1 & 1 & 30 & 0.3 & 0.38 & 0.36 & 350 & 350 & 350 & 1000 & 1 & 2 & 5 & 4.05 & 5.47 \\
\hline 96 & 1 & 1 & 100 & 0.35 & 0.33 & 0.36 & 350 & 350 & 350 & 10000 & 1 & 2 & 1.5 & 4.38 & 3.67 \\
\hline 97 & 1 & 1 & 30 & 0.3 & 0.33 & 0.36 & 420 & 420 & 350 & 10000 & 1 & 2 & 1.5 & 3.75 & 3.7 \\
\hline 98 & 1 & 1 & 30 & 0.3 & 0.33 & 0.4 & 420 & 420 & 420 & 1000 & 5 & 9 & 1.5 & 3.36 & 3.31 \\
\hline 99 & 1 & 1 & 30 & 0.35 & 0.38 & 0.4 & 350 & 350 & 350 & 10000 & 1 & 9 & 5 & 3.45 & 3.85 \\
\hline 100 & 1 & 1 & 30 & 0.35 & 0.33 & 0.36 & 350 & 420 & 420 & 10000 & 1 & 2 & 5 & 4.11 & 6.22 \\
\hline 101 & 1 & 1 & 100 & 0.35 & 0.38 & 0.4 & 420 & 350 & 420 & 10000 & 5 & 2 & 1.5 & 3.99 & 4.24 \\
\hline 1000 & 1 & 1 & 100 & 0.3 & 0.33 & 0.36 & 420 & 350 & 350 & 1000 & 1 & 2 & 1.5 & 4.08 & 4.09 \\
\hline 103 & 1 & 1 & 30 & 0.3 & 0.38 & 0.36 & 350 & 350 & 420 & 10000 & 1 & 2 & 1.5 & 3.36 & 4.93 \\
\hline 10000 & 1 & 1 & 30 & 0.3 & 0.33 & 0.36 & 350 & 350 & 350 & 10000 & 5 & 9 & 1.5 & 3.3 & 3.1 \\
\hline 105 & 1 & 1 & 30 & 0.35 & 0.38 & 0.36 & 420 & 350 & 420 & 1000 & 1 & 2 & 1.5 & 3.33 & 4.69 \\
\hline 106 & 1 & 1 & 30 & 0.3 & 0.38 & 0.36 & 350 & 420 & 350 & 1000 & 1 & 9 & 1.5 & 3.72 & 2.83 \\
\hline 107 & 1 & 1 & 30 & 0.35 & 0.33 & 0.36 & 420 & 420 & 420 & 10000 & 5 & 2 & 1.5 & 3.6 & 3.91 \\
\hline 108 & 1 & 1 & 100 & 0.3 & 0.38 & 0.36 & 350 & 420 & 350 & 10000 & 1 & 2 & 5 & 4.74 & 4.96 \\
\hline 109 & 1 & 1 & 100 & 0.35 & 0.38 & 0.36 & 420 & 420 & 420 & 10000 & 1 & 2 & 1.5 & 4.32 & 3.97 \\
\hline 110 & 1 & 1 & 100 & 0.35 & 0.38 & 0.4 & 420 & 420 & 420 & 10000 & 5 & 9 & 5 & 4.38 & 3.67 \\
\hline 111 & 1 & 1 & 30 & 0.35 & 0.38 & 0.36 & 420 & 420 & 350 & 10000 & 1 & 9 & 1.5 & 3.39 & 2.89 \\
\hline 112 & 1 & 1 & 100 & 0.35 & 0.38 & 0.36 & 420 & 350 & 350 & 1000 & 1 & 9 & 1.5 & 3.84 & 3.67 \\
\hline 113 & 1 & 1 & 30 & 0.3 & 0.38 & 0.4 & 420 & 420 & 350 & 1000 & 1 & 2 & 1.5 & 3.81 & 4.21 \\
\hline 114 & 1 & 1 & 100 & 0.3 & 0.38 & 0.36 & 350 & 350 & 350 & 10000 & 1 & 9 & 1.5 & 4.47 & 2.92 \\
\hline 115 & 1 & 1 & 30 & 0.3 & 0.38 & 0.4 & 420 & 350 & 420 & 10000 & 1 & 9 & 1.5 & 2.94 & 3.82 \\
\hline 116 & 1 & 1 & 100 & 0.3 & 0.33 & 0.4 & 350 & 420 & 350 & 1000 & 1 & 2 & 5 & 5.13 & 4.93 \\
\hline 117 & 1 & 1 & 30 & 0.3 & 0.38 & 0.4 & 420 & 350 & 350 & 1000 & 1 & 9 & 5 & 3.36 & 3.88 \\
\hline 118 & 1 & 1 & 100 & 0.3 & 0.38 & 0.4 & 350 & 350 & 350 & 10000 & 5 & 2 & 5 & 4.44 & 5.23 \\
\hline
\end{tabular}




\begin{tabular}{cccccccccccccccc}
\hline Run Order & CenterPt & Blocks & $\boldsymbol{u}_{\boldsymbol{t}}$ & $\boldsymbol{X}_{\boldsymbol{b a} \mathbf{1}}$ & $\boldsymbol{X}_{\boldsymbol{b a 2} \mathbf{2}}$ & $\boldsymbol{X}_{\boldsymbol{b a} \mathbf{3}}$ & $A S_{\mathbf{1}}$ & $A S_{\mathbf{2}}$ & $A S_{\mathbf{3}}$ & $\boldsymbol{T}_{\text {out }}$ & $\boldsymbol{C}_{\boldsymbol{g h}}$ & $\boldsymbol{C}_{\boldsymbol{g}}$ & $\boldsymbol{C}_{\boldsymbol{s}}$ & $\boldsymbol{u}_{\mathbf{2}}$ & $\boldsymbol{u}_{\mathbf{3}}$ \\
\hline 119 & 1 & 1 & 100 & 0.3 & 0.33 & 0.4 & 350 & 420 & 420 & 10000 & 1 & 2 & 1.5 & 4.62 & 4.48 \\
120 & 1 & 1 & 100 & 0.35 & 0.33 & 0.36 & 350 & 420 & 350 & 10000 & 1 & 9 & 5 & 5.01 & 3.04 \\
121 & 1 & 1 & 100 & 0.3 & 0.33 & 0.36 & 420 & 420 & 420 & 10000 & 1 & 9 & 1.5 & 4.17 & 3.82 \\
122 & 1 & 1 & 100 & 0.3 & 0.33 & 0.36 & 350 & 350 & 420 & 10000 & 5 & 2 & 1.5 & 4.17 & 4.72 \\
123 & 1 & 1 & 100 & 0.3 & 0.38 & 0.4 & 350 & 420 & 350 & 10000 & 5 & 9 & 1.5 & 5.19 & 2.59 \\
124 & 1 & 1 & 30 & 0.35 & 0.38 & 0.36 & 350 & 420 & 420 & 1000 & 5 & 9 & 1.5 & 3.66 & 3.04 \\
125 & 1 & 1 & 100 & 0.3 & 0.38 & 0.36 & 420 & 420 & 420 & 1000 & 5 & 2 & 5 & 4.65 & 4.78 \\
126 & 1 & 1 & 30 & 0.35 & 0.33 & 0.4 & 420 & 420 & 350 & 1000 & 1 & 9 & 1.5 & 3.42 & 2.98 \\
127 & 1 & 1 & 30 & 0.3 & 0.38 & 0.4 & 420 & 420 & 420 & 10000 & 1 & 2 & 5 & 4.11 & 5.83 \\
128 & 1 & 1 & 100 & 0.3 & 0.38 & 0.36 & 420 & 350 & 350 & 10000 & 5 & 9 & 5 & 4.02 & 3.55 \\
\hline
\end{tabular}

\section{References}

1. Hong, T.T.; Cuong, N.V.; Ky, L.H.; Tuan, N.K.; Pi, V.N. Calculating optimum gear ratios of two step bevel helical reducer. Int. J. Appl. Eng. Res. 2019, 14, 3494-3499.

2. Kudreavtev, V.N.; Gierzaves, I.A.; Glukharev, E.G. Design and Calculus of Gearboxes; Mashinostroenie Publishing: Moscow, Russia, 1971. (In Russian)

3. Pi, V.N. A new study on optimal calculation of partial transmission ratios of two-step helical gearboxes. In Proceedings of the 2nd WSEAS International Conference on Computer Engineering and Applications, CEA'08, Acapulco, Mexico, 25-27 January 2008; pp. 162-165.

4. Pi, V.N. A new study on the optimal prediction of partial transmission ratios of three-step helical gearboxes with second-step double gear-sets. WSEAS Trans. Appl. Theor. Mech 2007, 2, 156-163.

5. Cam, N.T.H.; Pi, V.N.; Tuan, N.K.; Hung, L.X.; Thao, T.T.P. A study on determination of optimum partial transmission ratios of mechanical driven systems using a chain drive and a three-step helical reducer. In Advances in Engineering Research and Application; Fujita, H., Nguyen, D., Vu, N., Banh, T., Puta, H., Eds.; ICERA 2018. Lecture Notes in Networks and Systems; Springer: Cham, Switzerland, 2018; Volume 63, pp. 91-99. [CrossRef]

6. Cuong, N.V.; Ky, L.H.; Hong, T.T.; Tu, N.T.; Pi, V.N. Splitting Total Gear Ratio of Two-Stage Helical Reducer with First-Stage Double Gearsets for Minimal Reducer Length. Int. J. Mech. Prod. Eng. Res. Dev. 2019, 9, 595-608.

7. Pi, V.N.; Tuan, N.K. Determining optimum partial transmission ratios of mechanical driven systems using a chain drive and a two-step bevel helical gearbox. Int. J. Mech. Eng. Rob. Res. 2019, 8, 708-712.

8. Hung, L.X.; Hong, T.T.; Cuong, N.V.; Ky, L.H.; Tu, N.T.; Cam, N.T.H.; Tuan, N.K.; Pi, V.N. Calculation of optimum gear ratios of mechanical driven systems using two-stage helical gearbox with first stage double gear sets and chain drive. In Advances in Engineering Research and Application; Sattler, K.U., Nguyen, D., Vu, N., Tien Long, B., Puta, H., Eds.; ICERA 2019. Lecture Notes in Networks and Systems; Springer: Cham, Switzerland, 2019; Volume 104, pp. 170-178. [CrossRef]

9. Thao, T.T.P.; Hong, T.T.; Cuong, N.V.; Ky, L.H.; Tu, N.T.; Hung, L.X.; Pi, V.N. Determining optimum gear ratios of mechanical driven systems using three stage bevel helical gearbox and chain drive. In Advances in Engineering Research and Application; Sattler, K.U., Nguyen, D., Vu, N., Tien Long, B., Puta, H., Eds.; ICERA 2019. Lecture Notes in Networks and Systems; Springer: Cham, Switzerland, 2019; Volume 104, pp. $249-261$. [CrossRef]

10. Tuan, N.K.; Hong, T.T.; Cuong, N.V.; Ky, L.H.; Tu, N.T.; Tung, L.A.; Hung, L.X.; Pi, V.N. A study on determining optimum gear ratios of mechanical driven systems using two-step helical gearbox with first step double gear sets and chain drive. In Advances in Engineering Research and Application; Sattler, K.U., Nguyen, D., Vu, N., Tien Long, B., Puta, H., Eds.; ICERA 2019. Lecture Notes in Networks and Systems; Springer: Cham, Switzerland, 2019; Volume 104, pp. 85-93. [CrossRef]

11. Tung, L.A.; Hong, T.T.; Cuong, N.V.; Ky, L.H.; Tu, N.T.; Thanh Tu, N.; Hung, L.X.; Pi, V.N. A study on determination of optimum gear ratios of a two-stage worm gearbox. In Advances in Engineering Research and Application; Sattler, K.U., Nguyen, D., Vu, N., Tien Long, B., Puta, H., Eds.; ICERA 2019. Lecture Notes in Networks and Systems; Springer: Cham, Switzerland, 2019; Volume 104, pp. 76-84. [CrossRef]

12. Trinh Chat, L.V.U. Calculation of Mechanical Driven Systems; Education Publisher: Hanoi, Vietnam, 2008. (In Vietnamse) 
13. Milou, G.; Dobre, G.; Visa, F.; Vitila, H. Optimal Design of two Step Gear Units, Regarding the Main Parameters; No 1230; VDI Berichte: Düsseldorf, Germany, 1996; pp. 227-235.

14. Pi, V.N.; Tuan, N.K. Optimum determination of partial transmission ratios of three-step helical gearboxes for getting minimum cross section dimension. J. Environ. Sci. Eng. A. 2016, 5, 570-573.

15. Cam, N.T.H.; Pi, V.N.; Hong, T.T.; Ky, L.H.; Tung, L.A. A Study On Calculation Of Optimum Gear Ratios Of A Two-Stage Helical Gearbox With Second Stage Double Gear Sets. Int. J. Mech. Prod. Eng. Res. Dev. 2019, 9, 599-606.

16. Pi, V.N.; Hong, T.T.; Thao, T.T.P.T.; Tuan, N.K.; Hung, L.X.; Tung, L.A. Calculating optimum gear ratios of a two-stage helical reducer with first stage double gear sets. In Proceedings of the 2018 the 6th International Conference on Mechanical Engineering, Materials Science and Civil Engineering, Xiamen, China, 21-22 December 2018; Volume 542.

17. Pi, V.N. A Study on Optimal Determination of Partial Transmission Ratios of Helical Gearboxes with Second Step Double Gear. World Acad. Sci. Eng. Technol. Int. J. Mech. Mechatron. Eng. 2008, 2, 26-29.

18. Tuan, N.K.; Pi, V.N.; Cam, N.T.H.; Thao, T.T.P.; Thanh, H.K.; Hung, L.X.; Tham, H.T. Determining optimal gear ratios of a two-stage helical reducer for getting minimal acreage of cross section. In Proceedings of the 2018 6th Asia Conference on Mechanical and Materials Engineering (ACMME 2018), MATEC Web of Conferences, Seoul, Korea, 15-18 June 2018; Volume 213. [CrossRef]

19. Pi, V.N. Optimal determination of partial transmission ratios for four-step helical gearboxes with first and third step double gear-sets for minimal mass of gears. In Proceedings of the Applied Computing Conference (ACC '08), Istanbul, Turkey, 27-30 May 2008; pp. 53-57.

20. Pi, V.N.; Thao, T.T.P.; Hong, T.T.; Tuan, N.K.; Hung, L.X.; Tung, L.A. Determination of optimum gear ratios of a three stage bevel helical gearbox. In Proceedings of the 2018 the 6th International Conference on Mechanical Engineering, Materials Science and Civil Engineering, Xiamen, China, 21-22 December 2018; Volume 542.

21. Pi, V.N. A new and effective method for optimal calculation of total transmission ratio of two step bevel-helical gearboxes. In Proceedings of the International Colloquium on Mechannics of Solids, Fluids, Structures \& Interaction, Nha Trang, Vietnam, 14-18 August 2000; pp. 716-771.

22. Pi, V.N.; Cam, N.T.H.; Tuan, N.K. Optimum calculation of partial transmission ratios of mechanical driven systems using a V-belt and two-step bevel helical gearbox. J. Environ. Sci. Eng. 2016, A5, 566-569.

23. Pi, V.N.; Thao, T.T.P.; Tuan, D.A. Optimum determination of partial transmission ratios of mechanical driven systems using a chain drive and two-step helical gearbox. J. Environ. Sci. Eng. 2017, B6, 80-83.

24. Cam, N.T.H.; Pi, V.N.; Tuan, N.K.; Hung, L.X.; Thao, T.T.P. Determining optimal partial transmission ratios of mechanical driven systems using a V-belt drive and a helical reducer with second-step double gear-sets. In Advances in Engineering Research and Application; Fujita, H., Nguyen, D., Vu, N., Banh, T., Puta, H., Eds.; ICERA 2018. Lecture Notes in Networks and Systems; Springer: Singapore, 2018; Volume 63, pp. 261-269.

25. Pi, V.N.; Tuan, N.K.; Hung, L.X.; Cam, N.T.H.; Thao, T.T.P. Determining optimum partial transmission ratios of mechanical driven systems using a V-Belt drive and a three-stage helical reducer. In Advances in Material Sciences and Engineering; Awang, M., Emamian, S., Yusof, F., Eds.; Lecture Notes in Mechanical Engineering; Springer: Singapore, 2020; pp. 81-88.

26. Romhil, I.; Linke, H. Gezielte auslegung von zahnradgetriben mit minimaler masse auf der basis neuer Berechnungsverfahren. Konstruktion 1992, 44, 229-236.

(C) 2020 by the authors. Licensee MDPI, Basel, Switzerland. This article is an open access article distributed under the terms and conditions of the Creative Commons Attribution (CC BY) license (http://creativecommons.org/licenses/by/4.0/). 